\title{
1 New insights into the evolution of SPX gene family from algae to legumes; a focus on soybean
}

2 Mahnaz Nezamivand Chegini ${ }^{1 *}$, Esmaeil Ebrahimie ${ }^{1,2,3}$, Ahmad Tahmasebi $^{4}$, Ali Moghadam ${ }^{1}$,

3 Saied Eshghi ${ }^{5}$, Manijeh Mohammadi-Dehchesmeh ${ }^{3}$, Stanislav Kopriva $^{6^{*}}$, Ali Niazi $^{1^{*}}$

$4{ }^{1}$ Institute of biotechnology, Shiraz university, Shiraz, Iran

$5 \quad{ }^{2}$ La Trobe Genomics Research Platform, School of Life Sciences, College of Science, Health and

6 Engineering, La Trobe University, Melbourne, VIC 3086, Australia

$7 \quad{ }^{3}$ School of Animal and Veterinary Sciences, The University of Adelaide, Adelaide, SA 5371,

8 Australia

$9{ }^{4}$ Department of Crop Production and Plant Breeding, College of Agriculture, Shiraz University,

10 Shiraz, Iran

$11{ }^{5}$ Department of Horticultural Science, School of Agriculture, Shiraz University, Shiraz, Iran

$12{ }^{6}$ Institute for Plant Sciences, Cluster of Excellence on Plant Sciences, University of Cologne,

13 Cologne, Germany

14 * Correspondence: niazi@shirazu.ac.ir, ma_nezami65@yahoo.com. 


\section{Abstract}

Background: SPX-containing proteins have been known as key players in phosphate signaling and homeostasis. In Arabidopsis and rice, functions of some SPXs have been characterized, but little is known about their function in other plants, especially in the legumes.

Results: We analyzed SPX gene family evolution in legumes and in a number of key species from algae to angiosperms. We found that SPX harboring proteins showed fluctuations in domain fusions from algae to the angiosperms with, finally, four classes appearing and being retained in the land plants. Despite these fluctuations, Lysine Surface Cluster (KSC), and the third residue of Phosphate Binding Sites (PBS) showed complete conservation in almost all of SPXs except few proteins in Selaginella moellendorffii and Papaver sumniferum, suggesting they might have different ligand preferences. In addition, we found that the WGD/segmentally or dispersed duplication types were the most frequent contributors to the SPX expansion, and that there is a positive correlation between the amount of WGD contribution to the SPX expansion in individual species and its number of EXS genes. We could also reveal that except SPX class genes, other classes lost the collinearity relationships among Arabidopsis and legume genomes. The sub- or neo-functionalization of the duplicated genes in the legumes makes it difficult to find the

31 functional orthologous genes. Therefore, we used two different methods to identify functional 32 orthologs in soybean and Medicago. High variance in the dynamic and spatial expression pattern of GmSPXs proved the new or sub-functionalization in the paralogs.

Conclusion: This comprehensive analysis revealed how SPX gene family evolved from algae to

35 legumes and also discovered several new domains fused to SPX domain in algae. In addition, we and $P$. sumniferum. Finally, we predicted putative functional orthologs of AtSPXs in the legumes, 
38 especially, orthologs of AtPHO1 and AtPHO1;H1, involved in long-distance Pi transportation.

39 These findings help to understand evolution of phosphate signaling and might underpin

40 development of new legume varieties with improved phosphate use efficiency.

41

42 Keywords: phosphate homeostasis, evolution, gene family, legumes 


\section{$44 \quad$ Background}

45 Phosphorus (P) as an essential macronutrient serves as a structural element for many organic

46 compounds, involved in multiple biosynthetic and metabolic processes [1, 2]. P containing

47 molecules play a central role in various physiological processes, including respiration,

48 photosynthesis, membrane transport, regulation of enzyme activity, oxidation-reduction reactions

49 and signal transduction throughout plant growth, and development $[3,4]$. Therefore, plants have

50 evolved a number of mechanisms to ensure that $\mathrm{P}$ is readily available for all these processes. In

51 particular, a wide range of responses are induced by phosphate (Pi) starvation $[5,6]$. The regulation

52 occurs at both transcriptional and posttranscriptional levels and many components of the

53 regulatory network are known. The central regulator of the Pi starvation response and signaling

54 network is the MYB transcription factor, AtPHR1 or OsPHR2 [7-9]. The PHR factors are

55 negatively regulated through interaction with SPX domain proteins, which serve as sensors of P-

56 status of the cells. In high $\mathrm{P}$ availability, inositol polyphosphates (PP-InsPs) bind to the basic

57 surface of SPX domain proteins and facilitate their binding to PHR. This interaction may sequester

58 PHR1 in the cytosol or prevent its association with DNA in the nucleus [10]. In low P supply, low

59 availability of PP-InsPs-SPX results in the release of PHR1 to translocate to nucleus and to activate

60 Pi starvation induced (PSI) genes [8]. Additionally, SPX domain proteins were shown to be

61 involved in nitrate-phosphate signaling crosstalk in rice where nitrate-dependent interaction with

62 NRT1.1B caused ubiquitination and degradation of OsSPX4 and consequently translocation of

63 OsPHR2 and OsNLP3 into nucleus to induce PSI genes and nitrate inducible genes, respectively

$64[11]$.

65 Despite the importance of SPX domain proteins in Pi signaling and nitrogen-dependent phosphate

66 homeostasis, the functionality of all these proteins is still unclear. SPX domain proteins are 
67 important components of plant Pi homeostasis and can be divided into four classes based on the

68 presence of extra domains: while class 1 only includes SPX domain, other three classes (SPX-

69 EXS, SPX-MFS, SPX-RING), contain extra EXS, MFS, or RING domains, respectively [6]. There

70 are four and six members of the SPX class 1 in Arabidopsis and rice, respectively [12, 13] as

71 AtSPX3 and OsSPX1 act as negative regulators of Pi starvation signaling [12, 13]. Indeed,

72 AtSPX1, localized in the nucleus, has a high binding affinity for AtPHR1 under high P condition

73 and prevents it from activation of the downstream Pi starvation-induced (PSI) genes [8]. The rice

74 OsSPX4 protein involved in the nitrate dependent regulation of Pi uptake [11] also belongs to this

75 class. The most functional variation was observed in the EXS class members, including AtPHO1

76 and AtPHO1;1 involved in long-distance Pi transport from roots to shoots [14, 15], AtPHO1;4

77 with a role in response of hypocotyls to blue light [16], seed size and flowering [17-19] and

78 AtPHO1;10 being induced by numerous stresses, such as local wounding [20, 21]. The Major

79 Facilitator Superfamily (MFS) domain confers transport activity, therefore, SPX-MFS class are

80 involved in both transport and signaling [22]. Finally, members of SPX-RING class are also called

81 Nitrogen Limitation Adaptation (NLA) proteins due to their first identified role in nitrogen

82 starvation resistance [23].

83 Recently, two other classes of SPX proteins, SPX-SLC and SPX-VTC, were characterized in algae

84 as involved in polyphosphate synthesis and its transportation into vacuoles [24]. These two classes

85 seem to be lost during the evolution of plants with shifting the type of phosphate storage from

86 polyP in algae to $\mathrm{Pi}$ in the later-diverging Streptophytes [24]. It seems there have been some extra

87 domains fused with SPX domain that might have been lost during the evolution of SPX proteins

88 and that have not been comprehensively explored yet [25]. 
89 Legumes (Fabaceae) are the second most important family of crop plants economically [26].

90 Characterization of the SPX gene family in legumes can be helpful to gain insights into

91 mechanisms of $\mathrm{Pi}$ homeostasis and thus underpin development of $\mathrm{P}$ efficient varieties. In this

92 study, we performed a comprehensive analysis of SPX proteins from several legume crops

93 (soybean, alfalfa, and common bean), and compared with species of more basal taxonomic groups

94 such as mosses (Phiscomitrella patens), liverworts (Marchantia polymorpha), lycophytes

95 (Selaginella moellendorffii), basal angiosperms (Papaver somniferum, Amborella trichopoda, and

96 Nymphaea colorata), Rhodophytes (Cyanidioschyzon merolae, Galdieria sulphuraria, and

97 Chondrus crispus), chlorophytes (Chlamydomonas reinhardtii and Ostreococcus lucimarinus),

98 and charophytes (Chara braunii). We analyzed SPX protein evolution through phylogenetic

99 analysis, conserved motif changes, and identification of ancestral motifs. In addition, because of

100 only a partial functional characterization of SPX in legumes [27-31], we identified their functional

101 orthologs with well-characterized SPXs from Arabidopsis thaliana. Since sequence-based

102 orthology identifications alone have weakness in the one-to-many or many-to-many orthologs,

103 expressologs identification was used as a complementary approach for functional ortholog

104 identification [32]. With the combination of these two methods, we identified the functional

105 orthologs of key regulators AtPHO1, AtPHO1;H1, AtSPX4, AtPHO1;H10, and AtNLA2 in the

106 three legumes. In addition, we identified novel domains in SPX proteins of algae and functionally

107 characterized SPX proteins in soybean and Medicago.

108 Results

109 Identification of SPX domain proteins from algae to legumes

110 While in several plant species four families of SPX proteins were characterized, much less is

111 known about these proteins in legumes: in soybean and common bean just 10 and 3 members of 
112 class 1 were characterized and no SPX proteins in M. truncatula. Therefore, we intended to

113 characterize this protein family in these legume species and set it into evolutionary context by

114 analysis of SPX proteins from algae and basal plants. Sequences of SPX proteins were obtained

115 by BLASTP searches at EnsemblPlants from the legumes (G. max, P. vulgaris, and M. truncatula),

116 moss (P. patens), liverwort (M. polymorpha), lycophyte (S. moellendorffii), basal angiosperms ( $P$.

117 somniferum, A. trichopoda, and N. colorata) rhodophytes (C. merolae, G. sulphuraria, and C.

118 crispus), chlorophytes (C. reinhardtii and O. lucimarinus), and charophytes (C. braunii) protein

119 databases using full-length amino acid sequences of SPXs from Arabidopsis (20 proteins). After

120 removing sequences lacking the SPX domains and redundant and partial sequences, we compiled

121 all SPX proteins in the latest version of protein database in EnsemblPlants for these 15 species.

122 Some proteins were shorter than 200 aa and were excluded from further analyses, including four

123 short proteins of soybean (GLYMA_12G154800, GLYMA_10G097000, GLYMA_09G098200,

124 GLYMA_20G032200), two partial proteins of common bean (PHAVU_010G0720001g,

125 PHAVU_010G0720000g), one protein of M. truncatula (MTR_8g058603). In addition, we

126 excluded one protein of M. truncatula (MTR_0262S0060), where its corresponding gene is located

127 on a scaffold but not chromosomes, and one protein of common bean (PHAVU_O07g1245000g),

128 which had different structure from other SPX genes. Finally, 34 SPX proteins in G. max, 19 in $M$.

129 truncatula, 17 in P. vulgaris, 22 in P. patens, 10 in M. polymorpha, 2 in C. merolae, 4 in $G$.

130 sulphuraria, 2 in $C$. crispus, 5 in C. reinhardtii, 2 in O. lucimarinus, 4 in C. braunii, 42 in $P$.

131 somniferum, 11 in A. trichopoda, 16 in N. colorata, and 31 in S. moellendorffii were identified

132 (Supplemental Table S1). Furthermore, the proteins were classified into the four subfamilies based

133 on their additional domains. Interestingly, in some algae and basal plants, we found extra domains

134 that have not been previously reported (Figure 1). Totally, among these species, class EXS was 


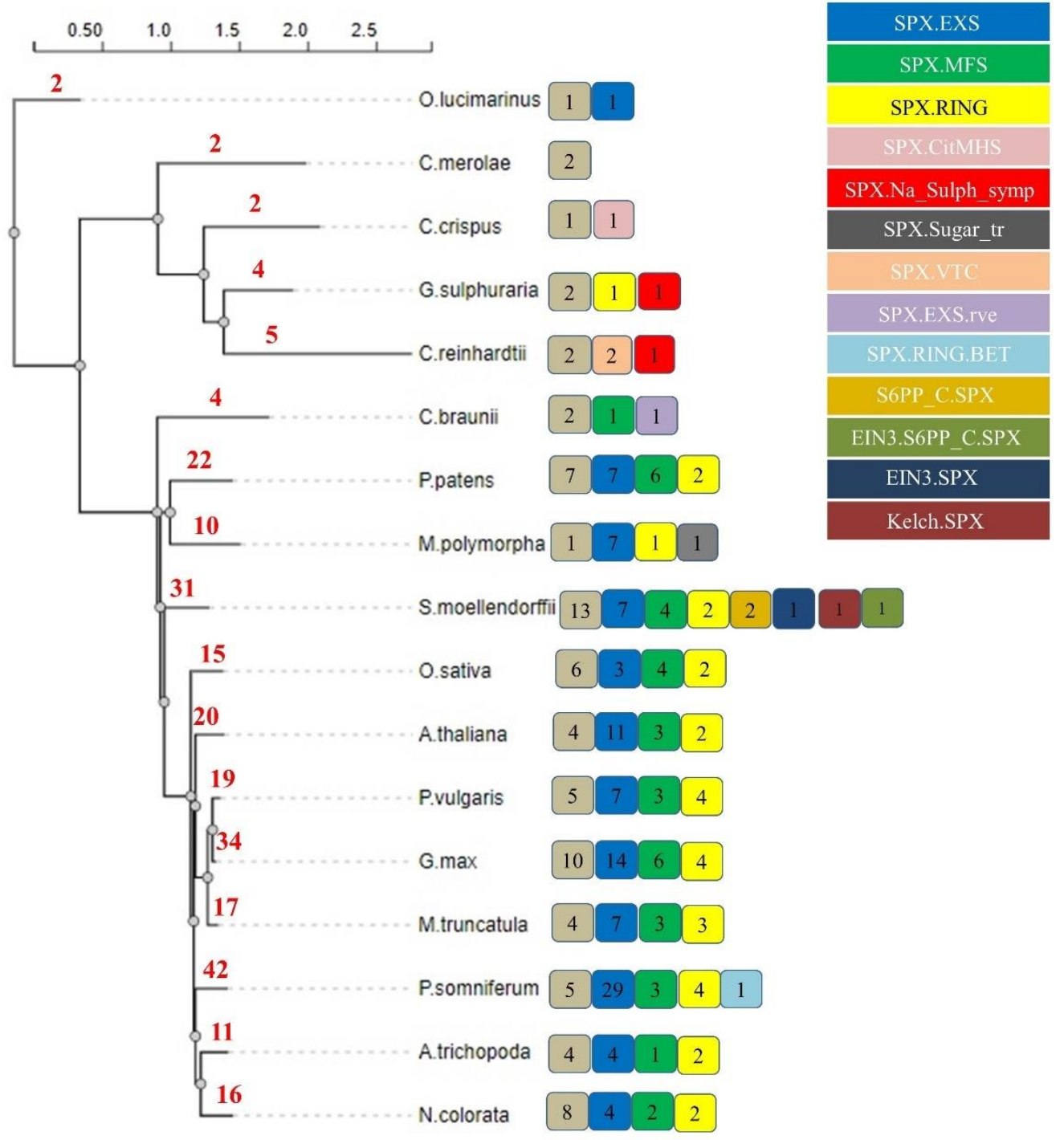

Figure 1. Evolution and frequency of genes in different SPX classes from algae to current Angiosperms. The species tree was constructed based on protein sequences of identified SPXs. Types of classes are shown in different colored boxes, the numbers in boxes represent the number of identified genes in each class while the total number of identified SPXs in each species is written in red on the branches. 
143 soybean, $M$. truncatula and common bean were named in each subfamily based on their

144 chromosomal positions (Supplemental Table S1).

145 As can be seen in the Figure 1, all basal and current angiosperms possess only the four main classes

146 of SPX proteins. On the other hand, some additional domains were observed in liverwort,

147 lycophyte, and algae based on Pfam and CDD scanning of sequences; SPX-VTC (vacuolar 148 transporter chaperone), EIN3-SPX (Ethylene intensive 3), SPX-CitMHS (Citrate transporter), 149 SPX-Na_sulph_symp (sodium sulphate symporter), SPX-RING-BET (Bromodomain extra150 terminal-transcription regulation), S6PP_C-SPX (Sucrose-6F-phosphate phosphohydrolase C151 terminal), EIN3-S6PP_C-SPX, Kelch-SPX (Galactose oxidase), SPX-EXS-rve, and SPX-Sugar_tr 152 (Figure 1). The exact roles of these additional domains in the basal plants and algae are not 153 completely known. It was previously reported that in some SPX proteins, SPX domain was located 154 at $\mathrm{C}$ terminal instead of $\mathrm{N}$ terminal [33]. Indeed, we observed this structure in 4 different classes in S. moellendorffii, including EIN3-S6PP_C-SPX, Kelch-SPX, EIN3-SPX, and S6PP_C-SPX.

Predicted physiochemical and biochemical parameters of these SPX proteins in legume crops are

157 listed in Supplemental Table S1. Indeed, members of the same subfamily have similar properties.

158 The most variation in physiochemical parameters was observed in EXS class, while MFS class 159 was the most similar. For example, lengths of all SPX-MFS proteins in the three species ranged from 691 to 700 aa, but the corresponding SPX-EXS proteins ranged from 475 to 1570 aa with the 161 MtEXSs having the largest proteins in comparison with soybean and common bean. SPX-EXS 162 and SPX-RING classes have the highest isoelectric point (pI), above 9 and 8, respectively. The 163 calculated values for aliphatic index of SPX proteins show that the SPX-MFS subfamily have most 164 thermostability, with a range of 105 to 111 . GRAVY value (grand average of hydropathicity) is 165 the sum of the hydropathy values of all amino acids divided by the protein length. Except for the 
166

167

168

169

170

171

172

173

174

175

176

177

178

179

180

181

182

183

proteins in the SPX-MFS subfamily, nearly all of the GmSPXs are hydrophilic, with a GRAVY value less than 0. Subcellular localization prediction performed with Wolf PSORT revealed that most of the GmSPX proteins are located in the plasma membrane or endomembrane system, followed by nucleus and chloroplast. In PSORT results, all members of SPX-EXS and SPX-MFS subfamilies were located in the plasma membrane, and all members of SPX-RING were located in nucleus, corresponding to the known functions of representatives of these subfamilies in Arabidopsis.

\section{Phylogenetic tree}

Multiple alignment of the SPX protein sequences from soybean, M. truncatula, common bean, Arabidopsis, rice, wheat, rapeseed, A. trichopoda, C. braunii, C. reinhardtii, C. crispus, C. merolae, G. sulphuraria, M. polymorpha, N. colorata, O. lucimarinus, P. somniferum, P. patens, and S. moellendorffii, as well as proteins from mouse, human, and Caenorhabditis elegans as an out-group, followed by phylogenetic analysis revealed four distinct clades of SPX proteins, SPX, EXS, MFS, and RING (Figure 2). This topology and distinct separation of four classes are consistent with previous studies on SPX gene family [3, 12, 13, 27, 34]. SPX and EXS sequences formed two distinct clades, while MFS and RING along with box. C (OSTLU26654.EXS, CHC T00007225001.SPX.CitMHS, CHLRE O9g251650V5.SPX.Na_Sulph_symp, C5167 020395.NLA.BET, GSu16460.SPX.NLA, and CMP022C.SPX) and box. D (Gsu35240.SPX.Na_sulph_symp) have diverged from a common ancestor and form the third major clade. SPX clade was divided into three sub-clades; SPX-I, SPX-II, and SPX-III. SPX-II and SPXIII are specific to the basal and current angiosperms and the proteins in these two sub-clades are homologs of AtSPX3 and ATSPX1/2, respectively. On the other hand, SPX-I is comprised from homologs of the basal plants (lycophytes, liverwort, moss) and algae and few proteins from the 


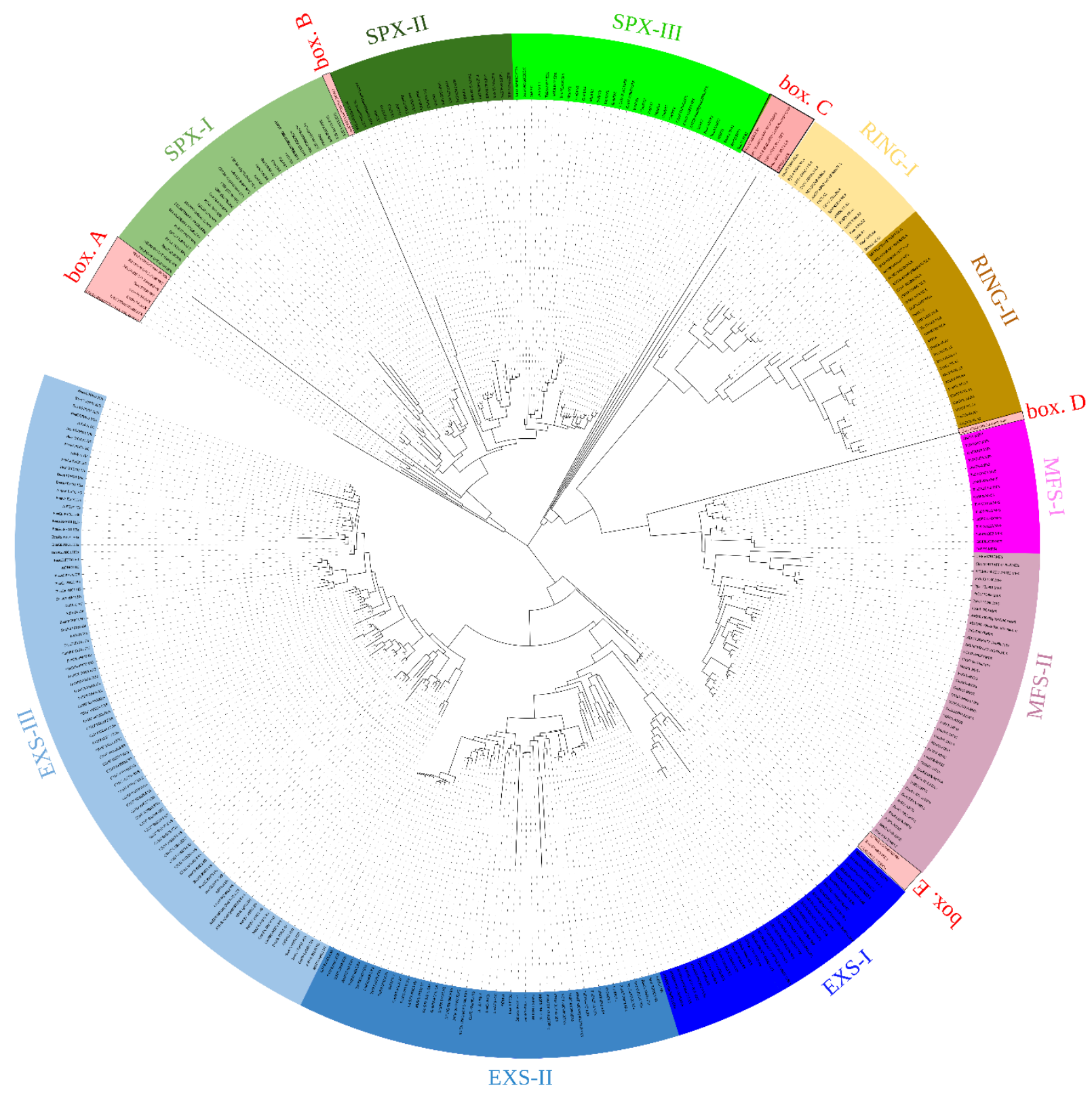

Figure 2. Phylogenetic analysis of 218 SPX containing proteins from 19 plant species. The phylogenetic tree was constructed using the Maximum Likelihood method. The SPX genes of Arabidopsis, rice, wheat, rapeseed, M. truncatula, soybean, and common bean are represented with At, Os, Ta, Bna, Mt, Gm, and Pv abbreviations, respectively. Other species are named based on their Gene IDs and their domains. Four different clades are marked in colors: SPX (green), RING (brown), MFS (pink), and EXS (blue). Subclades of each clade are shown with light and dark shades of the respective colors. Five boxes show paraphyletic branches; box E comprises the outgroup species. 
basal and current angiosperms, all being homologs of AtSPX4. Proteins in box A and in box B could be ancient homologs for SPX-I and SPX-II/III, respectively. Likewise, EXS clade was divided into three sub-clades; EXS-I is specific to lower plants (S. moellendorffii, M. polymorpha, and $P$. patens), EXS-II is a mixed group from monocots, eudicots, and basal angiosperms, all homologs of AtPHO1 and AtPHO1;H1, and EXS-III contain eudicots and the basal angiosperms without any genes of monocots. The outgroup genes used in this study were grouped in box E clustered with EXS clade. Overall, topology of EXS class is consistent with He et al., (2013), in that basal plants (lycophytes and moss) EXS homologs were grouped separately from the homologs for AtPHO1 and AtPHO1;H1 [6, 24, 35]. divergence of monocot and dicots from a common ancestor. Similarly, RING clade was divided

214 with the ancestor from $P$. patens, while RING-II included S. moellendorffii orthologs as its sister.

215 The overall tree topology is very similar to results of Wang et all (2021), who investigated SPX 216 gene family in chlorophytes and streptophytes, with focus on algae.

\section{Protein motifs gain and loss in SPX family throughout evolution}

218 Conserved protein motifs were predicted using MEME program for each SPX protein class and all 
221 The ancestral motifs in SPX domains such as motifs 3, 4, 2, and 1 seem to originate from red algae

222 (Additional file 1: Figure S1). There is a high fluctuation of motif composition during the

223 evolution. Some motifs are species specific like motifs 13, 14, and 19 that are present only in

224 legumes, probably arising after legume whole-genome duplication event. The most variability in

225 the motif composition was observed in S. moellendorffii with some specific motifs like 8, 15, and

226 18. The lengths of proteins in angiosperms were very similar but shorter than in the basal plants.

227 The EXS domain was detected only in $O$. lucimarinus with 9 motifs - 9, 6, 5, 2, 3, 11, 4, 10, and 1

228 (Additional file 1: Figure S2). Almost all these motifs have been retained during the evolution as

229 ancestral motifs. In addition, some other motifs appeared in $C$. braunii such as 15, 7, 16, 20, 12,

and 8, suggesting they were present in the common ancestor of Chlorophyta and Streptophyta.

231 Although Wang et al [24] reported one SPX-MFS in M. polymorpha genome, we could not find

232 an intact SPX-MFS domain, but SPX-Sugar_tr domain with a highly similar motif composition

233 with other MFSs was identified (Additional file 1: Figure S3). As it has previously been reported,

234 PHT5 genes in B. napus have SPX domain connected to overlapping MFS and Sugar_tr domains

235 [36], however, we only found SPX and Sugar-tr domains in M. polymorpha genome. The first

236 SPX-MFS protein was observed in C. braunii with 18 common motifs with other species. Two

237 newly observed motifs in $P$. patens, motifs 16 and 13 , probably have evolved by dispersed

238 duplication in $P$. patens and have been retained in all basal and current angiosperms. Interestingly,

239 other five MFSs in $P$. patens, without the motifs 16 and 13, have been no longer found in

240 angiosperms.

241 The evolutionary oldest NLA has been detected in G. sulphuraria and it was retained during the

242 course of evolution of current angiosperms, but was not found in other Rhodophytes or

243 Chlorophytes. In fact, the only NLA identified in G. sulphuraria just showed two motifs in 
244 common with other species, motifs 2 and 3 (Additional file 1: Figure S4). Therefore, these motifs

245 could be considered as ancestral motifs of NLA class which then further evolved by dispersed

246 duplication in $M$. polymorpha, adding motifs 8, 7, 1, and 6 into the ancestral domains. One NLA

247 in P. somniferum underwent dispersed duplication and gained motif 10 that has only been retained

248 in the core eudicots, while two NLAs in S. moellendorffii segmentally duplicated and gained two

249 specific motifs 13 and 19. Motif 16 was just observed in legume genomes that might evolved after

250 legume whole-genome duplication (WGD) event. The most variability in motif composition of

251 NLA class was observed in P. somniferum. Motif compositions in the new identified classes

252 showed a high variation and it was impossible to find their ancestral motif (Additional file 1: Figure

253 S5). However, it could be concluded that SPX-Na_Sulph_sym and SPX-CitMHS with high

254 similarity in the motif composition, probably have similar origin and function. In summary, during

255 the evolution different duplication events added new motifs to the ancestral motifs and other motifs

256 specifically appeared in individual species to acquire new functions.

\section{Consensus sequences of SPX domains from algae to eudicots}

258 We then predicted conserved motifs among all identified SPXs (Additional file 1: Figure S6).

259 There are four conserved motifs in SPX class members, among them two motifs, 2 and 4, are

260 common in the almost whole span of SPXs. Therefore, we can hypothesize that these two motifs

261 have an important role for all SPXs. Afterwards, consensus sequences of these two motifs were

262 constructed across all phyla (algae, charophytes, liverwort, bryophytes, lycophytes, basal

263 angiosperms, and current angiosperms) and also across each class (SPX, EXS, MFS, RING, and

264 new identified classes) (Additional file 1: Figure S7-S10). Motif 4 is 29 aa in length and was

265 present in all SPX proteins except the following ten: C5167_005902.EXS, C5167_032842.EXS,

266 C5167_043562.EXS， C5167_043565.EXS， C5167_003186.NLA， C5167_046257.NLA, 

amino acid residues, number 5, 9, 15, 19, and 24, were almost $100 \%$ conserved, except the fifth

273 positions with a very high overall conservation in this class. In addition, each class had other

274 conserved residues, suggesting special functions.

275 Motif 2 is 21 aa long and was absent in CHLRE_02g111650v5.SPX, 276 AMTR_s00106p00066860.SPX, NC1G0101580.SPX, C5167_011965.SPX, Gasu_57230.SPX, motif 2 and residues 14, 18, and 21 were conserved in the all proteins except a few in $S$. moellendorffii and P. sumniferum showing different residues instead of lysine (Additional file 1:

283 Figure S9). The lysine residues 14, 17, and 21 form a Lysine Surface Cluster (LSC), and were 284 found to interact with sulfate in the crystal structure of human phosphate transporter XPR1, and to 285 be a part of a larger binding site for PP-InsP [9]. Consequently, in the different classes of the SPX 286 proteins (Additional file 1: Figure S10), some of the 10 conserved positions were completely 287 conserved such as K1, N8, KILKK (14 to 18) in RING and MFS, K18 in SPX, K21 in RING, and $288 \mathrm{~N} 8, \mathrm{I15}, \mathrm{K} 18$, as well as K21 were completely conserved across the new identified classes. Overall, 
PvPHO1;5, and OsSPX4, implying that they might possibly interact with InsP/PP-InsP in a different manner, as previously reported for OsSPX4 [9]. In addition, different conserved residues in different classes could suggest that they may have different phosphate-containing ligand or different levels of Pi in cells

\section{Expansion pattern of SPX genes and collinearity analysis}

To pinpoint the expansion modes in the land plants, we investigated duplication types in basal and current angiosperms, liverwort, hornwort, and S. moellendorffii (Figure 3 and Supplemental Table gene family expansion. The expansion patterns in soybean, P. somniferum, $N$. colorota, and $S$. moellendorffii mostly arose from WGD/segmental duplication type. However, S. moellendorffii did not have any WGD events, therefore, its expansion and unique SPX classes must have arisen through local or segmental gene duplication [37]. WGD/segmental duplication type did not participate in the SPX expansion in A. trichopoda and M. polymorpha genomes and it only resulted in one duplicated block in $P$. patens genome. In these three species, SPX expansion were affected mostly by dispersed duplication type. The high number of WGD/segmental types of duplication in S. moellendorffii, soybean, and P. somniferum can shed light on the reason of high variation of gene family sizes in the closely related plants.

307 To get more information about evolutionary process of genes, collinearity analysis can provide information about conserved genomic regions of genes in different species [38]. Synteny relationship among two or a set of genes from two species means that they located in the same chromosome [39], but collinearity is a specific form of synteny with conserved gene order [40].

311 Collinearity analysis was conducted in three steps; 1. across P. somniferum, N. colorota, rice, 
Arabidopsis, and three legumes 2. Among P. somniferum and N. colorota, P. patens, and $S$.

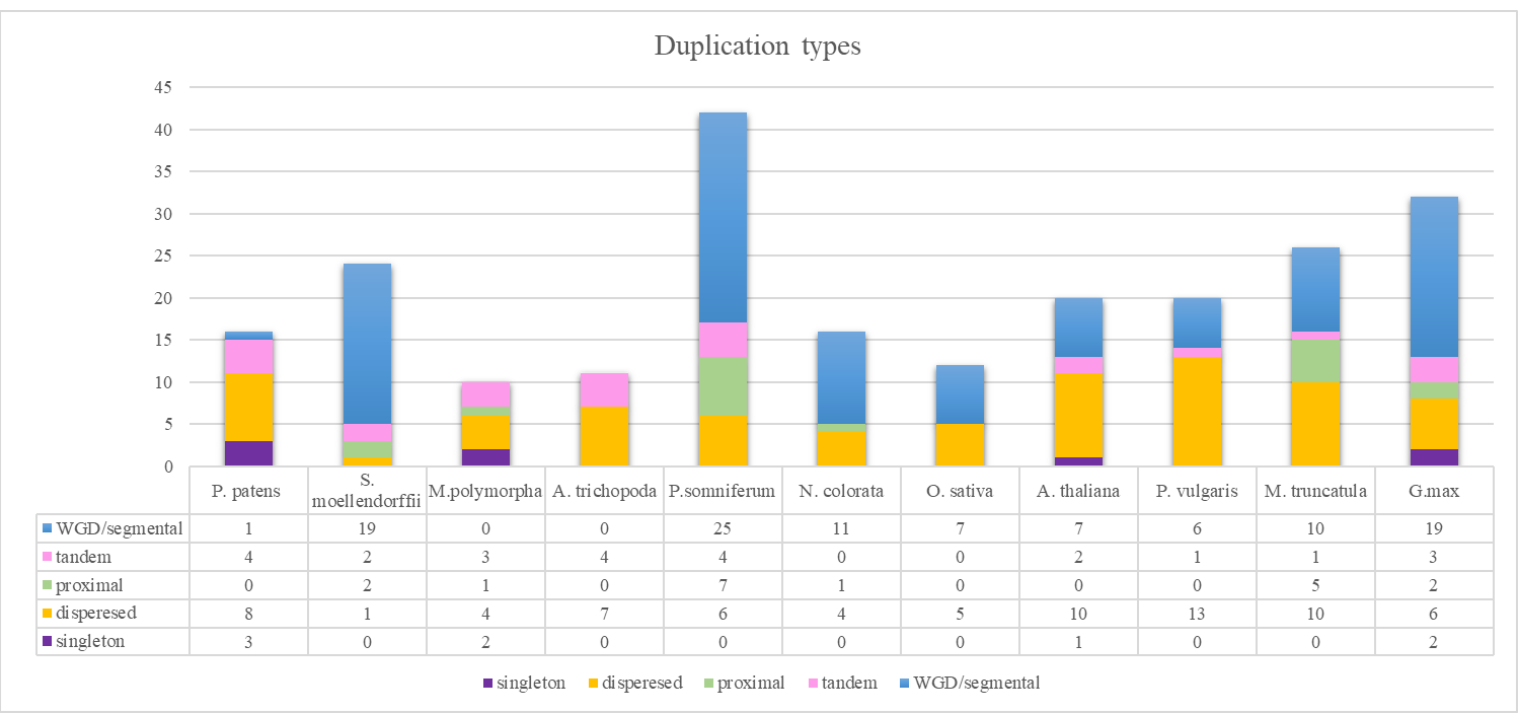

Figure 3. SPX gene family expansion from algae to the current Angiosperms. Duplication event types were predicted in the $P$. patens, S. moellendorffii, M. polymorpha, A. trichopoda, P. somniferum, N. colorota, O. sativa, A. thaliana, P. vulgaris, M. truncatula, G. max.

Collinearity analysis among legume crops, Arabidopsis, rice, and two basal angiosperms; $P$. somniferum and N. colorata discovered 121 collinear blocks (Figure 4, Supplemental Table S3); 30 blocks in $\mathrm{Gm} / \mathrm{Pv}, 23$ blocks in $\mathrm{Gm} / \mathrm{Mt}, 15$ blocks in $\mathrm{Gm} / \mathrm{Gm}, 14$ blocks in Ps/Ps, 10 blocks in Gm/At, 6 blocks in Nc/Nc and Pv/Mt, 3 blocks in Ps/Nc, Mt/At, Pv/At, and Os/Os, 2 blocks in $\mathrm{Ps} / \mathrm{Gm}$, and 1 block in $\mathrm{At} / \mathrm{At}, \mathrm{Pv} / \mathrm{Pv}, \mathrm{Ps} / \mathrm{Mt}$, and Mt/Mt. Rice as the only monocot in this analysis did not show any collinearity relationship for SPX gene family with other species. with other species, while $N$. colorata and $P$. somniferum had the most inter species collinear relationships (14). The most intra-genome collinear relationships were found in $P$. somniferum 
bioRxiv preprint doi: https://doi.org/10.1101/2021.08.24.457498; this version posted August 24, 2021. The copyright holder for this preprint (which was not certified by peer review) is the author/funder, who has granted bioRxiv a license to display the preprint in perpetuity. It is made available under aCC-BY-NC 4.0 International license.

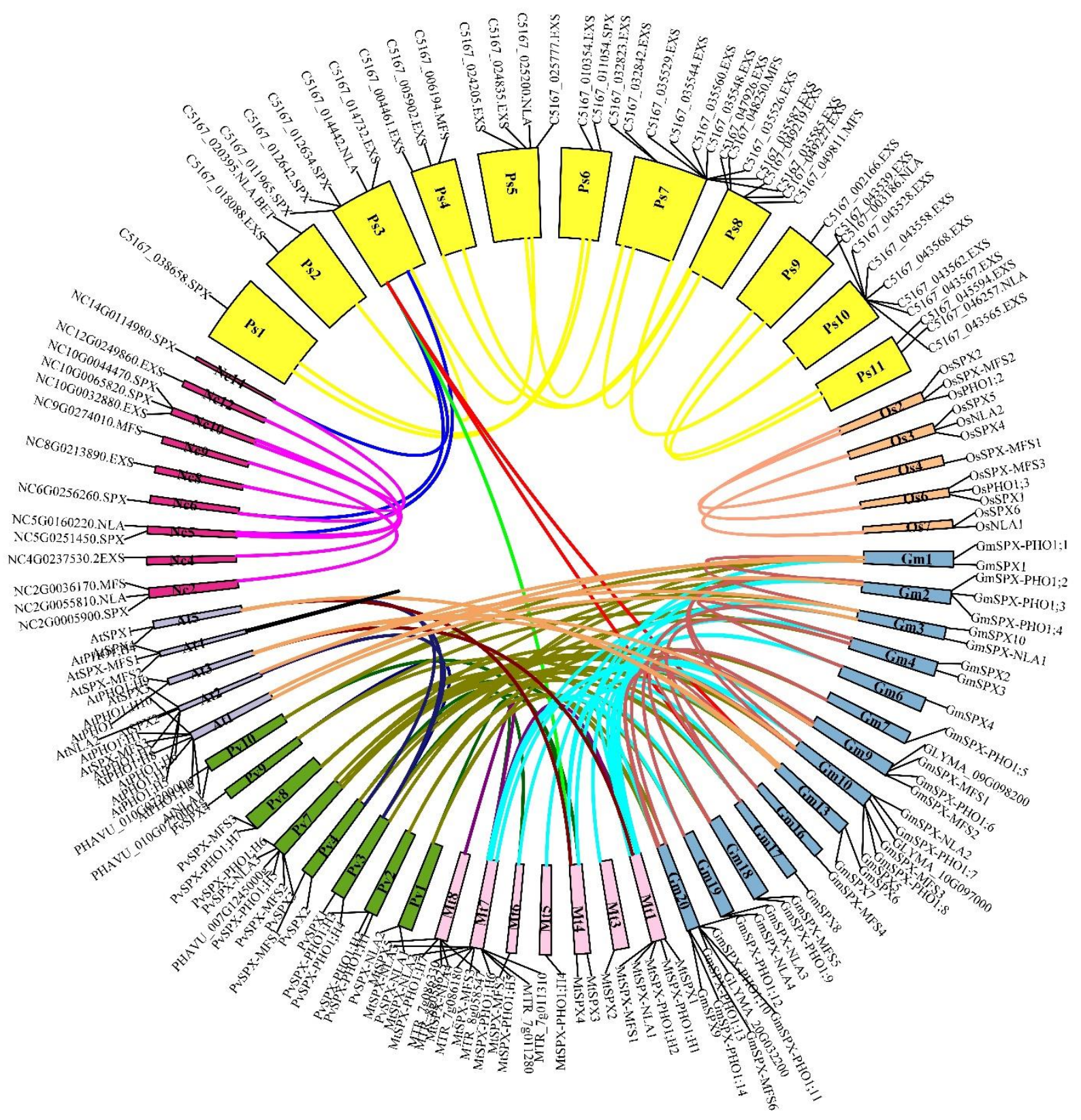

Figure 4. Circular collinearity plot of SPX gene family members among G. max (blue), M. truncatula (pink), P. vulgaris (green), A. thaliana (grey), O. sativa (orange), P. somniferum (yellow), and $N$. colorota (red). Collinear genes are linked by lines and boxes are representing chromosomes. 
bioRxiv preprint doi: https://doi.org/10.1101/2021.08.24.457498; this version posted August 24, 2021. The copyright holder for this preprint (which was not certified by peer review) is the author/funder, who has granted bioRxiv a license to display the preprint in perpetuity. It is made available under aCC-BY-NC 4.0 International license.

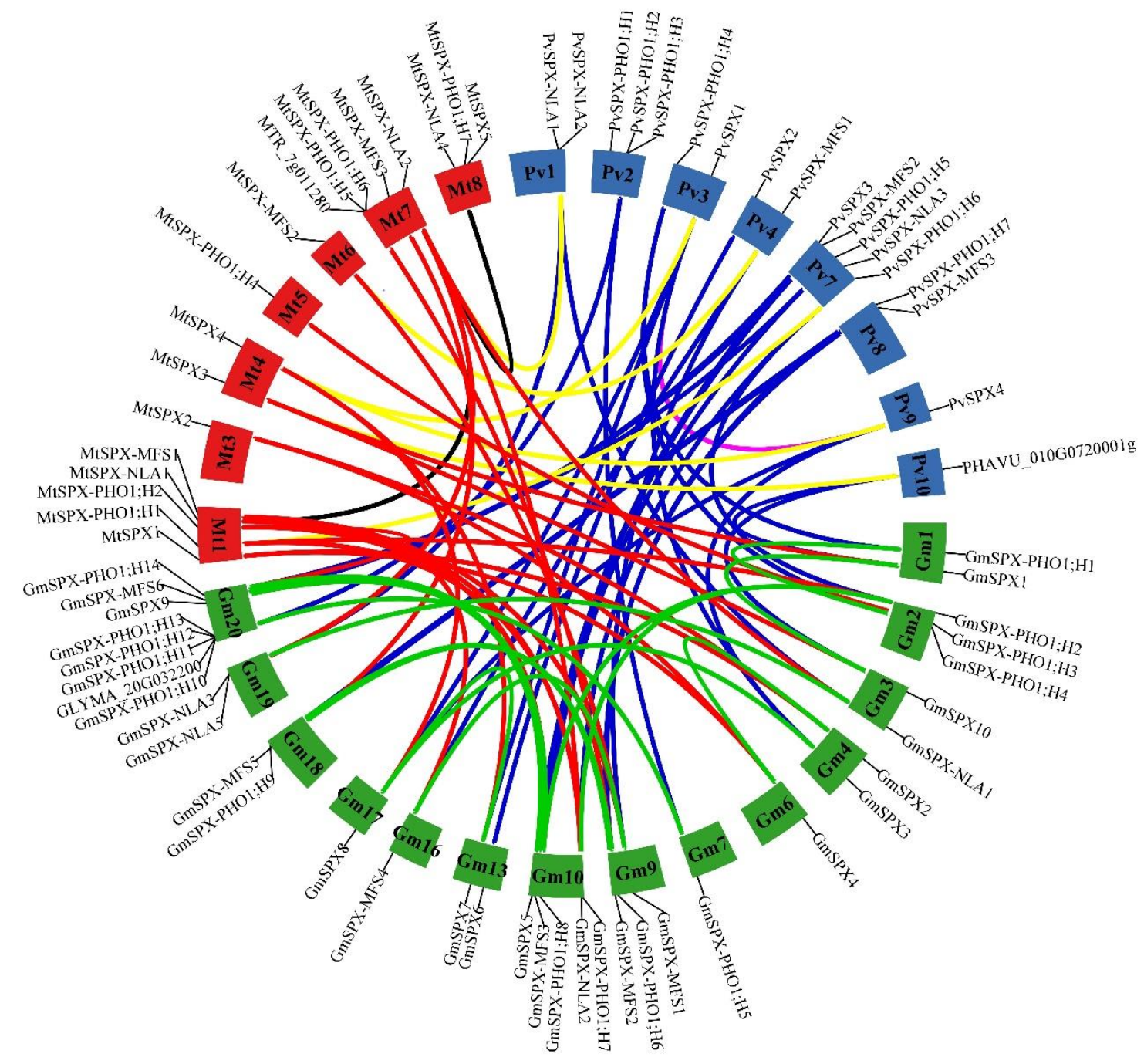

Figure 5. Circular collinearity plot of SPX gene family members among G. max, M. truncatula, P. vulgaris. Chromosomes of G. max, M. truncatula and P. vulgaris are respectively in green, red and blue. Links between G. max and M. truncatula are colored red, G. max and P. vulgaris in blue, M. truncatula and $P$. vulgaris in yellow as well as links within G. max, M. truncatula and $P$. vulgaris are colored in green, black and pink. relationships was found at 27/30 SPX genes in soybean/common bean and 19/23 SPX genes in 
344 soybean/M. truncatula, while the corresponding figure for M. truncatula/common bean was 6/7.

345 However, just 15, 7, and 2 collinearity blocks were found in soybean/soybean, M. truncatula IM.

346 truncatula, and common bean/common bean groups. All in all, after these three collinearity

347 analyses, we concluded that inter-species collinearity patterns among basal angiosperms and

348 among current angiosperms have changed. Across basal angiosperms, SPX class had the least

349 inter-species collinearity, while among Arabidopsis and legumes, SPX showed the most inter-

350 collinearity relationships. It can be concluded that except in SPX class, collinearity in the other

351 classes has been lost.

352 Evolution of Cis-acting elements from algae to eudicots

353 Transcription factors bind to the cis-acting elements (CREs) in the promoter and regulate the

354 transcription of corresponding genes [41]. Therefore, genes with similar expression patterns may

355 contain the same regulatory elements in their promoters [27]. To explore whether transcription

356 factor biding sites have evolved together with the coding regions of SPX genes, $1.5 \mathrm{~kb}$ upstream

357 of the transcriptional start sites of all identified SPXs were downloaded and analyzed using

358 PlantCARE database. In total, 124 CREs were detected (Supplemental Table S4) that can be

359 classified in three major groups: responsive to abiotic stresses (drought, low temperature, hypoxia,

360 wounding, defense, and stress), hormones (gibberellin, abscisic acid (ABA), salicylic acid (SA),

361 ethylene, methyl jasmonate (MeJA), and auxin), and development-related elements (endosperm,

362 meristem, MYB, and zein metabolism regulation). After the essential elements in promoter like

363 TATA-box and CAAT-box, the most highly represented cis-acting elements were those involved

364 in response to MeJA (CGTCA-motif and TGAG-motif) and ABA (ABRE and ARE). Looking for

365 evolutionary pattern in these cis-acting elements, we performed hierarchical clustering on principal 
367 (Additional file 1: Figure S11).

Table 1. Number of genes having MeJA and ABA responsiveness elements in their promoter sequence.

\begin{tabular}{|c|c|c|c|c|c|c|}
\hline Clusters & $\begin{array}{l}\text { TGACG- } \\
\text { motif }\end{array}$ & $\begin{array}{l}\text { CGTCA- } \\
\text { motif }\end{array}$ & ABRE & ARE & $\begin{array}{c}\text { Number of SPXs of } \\
\text { each species }\end{array}$ & Total \\
\hline Cluster 1 & 57 & 57 & 59 & 72 & $\begin{array}{l}16 \mathrm{At}, 27 \mathrm{Gm}, 12 \mathrm{Mt} \\
15 \mathrm{Pv}, 11 \mathrm{Pp}, 1 \mathrm{CHb}, 2 \\
\text { Gsu, } 4 \mathrm{Nc}, 2 \mathrm{Pp}, 1 \mathrm{Mp},\end{array}$ & 91 \\
\hline Cluster 2 & 55 & 55 & 32 & 47 & $\begin{array}{c}5 \text { CHLRE, } 2 \mathrm{Gsu}, 7 \mathrm{Mp} \text {, } \\
13 \mathrm{Ps}, 2 \mathrm{CHb}, 7 \mathrm{Nc}, 12 \\
\text { Pp, } 3 \mathrm{Sm}, 2 \mathrm{Mt}, 3 \mathrm{Gm}, 3 \\
\text { At }\end{array}$ & 59 \\
\hline Cluster 3 & 12 & 12 & 11 & 12 & $\begin{array}{c}3 \mathrm{Pp}, 1 \mathrm{Mp}, 1 \mathrm{Sm}, 1 \mathrm{At} \\
6 \mathrm{Ps}\end{array}$ & 12 \\
\hline
\end{tabular}

370 Almost all SPXs from the current angiosperms fell into cluster 1 along with 2 SPXs of $G$.

371 sulphuraria and few SPXs from basal angiosperms (Table 1, Additional file 1: Figure S11). Cluster

3722 comprised mostly genes from basal angiosperms and few members of the current angiosperms,

373 as well as all SPXs of C. reinhardtii and two SPXs from G. sulphuraria. Cluster 3, the smallest

374 cluster, had 12 genes mostly from P. patens and just one SPX of the current angiosperms, 375 AtPHO1; H5. Trying to find an evolutionary pattern across these clusters, we found out that they 376 showed different frequencies of two MeJA responsive elements, TGACG and CGTGA motifs, that 377 in cluster 3 all genes, in cluster 2 around 93\%, and in cluster 1 only around $62 \%$ of genes possessed 
378 these two elements (Table 1). Besides, we extracted the most enriched CREs in each cluster to

379 visualize frequencies of these elements across clusters. As can be seen in the Additional file 1:

380 Figure S12, CREs involved in the developmental processes (CCGTCC motif, CCGTCC box, A381 box) and stress response (DRE core, MYB recognition site, CCAT box) were significantly higher

382 in cluster 2 than in the other clusters. Cluster 1 had higher frequency of two hormone responsive

383 elements, TCA (salicylic acid responsive elements) and ERE (Ethylene-responsive elements) in

384 comparison to the other clusters. Overall, it seems that during the evolution of angiosperms, SPX

385 promoters were enriched by stress responsive elements and hormonal responsive elements, 386 especially ERE and TCA.

\section{Selective pressure and SPX history model in legumes}

389 The Ks (number of synonymous substitutions per synonymous site) and Ka (number of 390 nonsynonymous substitutions per nonsynonymous site) values of pairs of segmental duplicated 391 SPX genes in soybean, M. truncatula and common bean were retrieved from Plant Genome 392 Duplication Database (PGDD) (Supplemental Table S5). The Ka/Ks ratios < 1 indicate purifying 393 selection and $\mathrm{Ka} / \mathrm{Ks}$ values $>1$ indicate positive selection $[42,43]$. The $\mathrm{Ka} / \mathrm{Ks}$ values for all pairs 394 of segmental duplicated genes were $<0.3$ implying an intense purifying selection on these gene 395 pairs (Supplemental Table S5). In addition, the $\mathrm{Ka} / \mathrm{Ks}$ ratio of duplicated gene pairs between 396 soybean and M. truncatula, soybean and common bean, and M. truncatula and common bean were

397 retrieved (Supplemental Table S5). The mean Ka/Ks values of 0.18, 0.16, and 0.14, respectively, 398 suggest that the genetic pairs between species were subjected to purifying selection. 
Based on the Ks values of duplication blocks retrieved from PGDD, the divergence times were estimated. In total, 36, 7, and 3 duplication blocks were retrieved for soybean, $M$. truncatula, and common bean, respectively (Supplemental Table S5). All duplication blocks related to MFS and RING class have Ks $<1.5$, and the most recent duplication events belonged to MFS members in soybean. Evolutionary process of GmSPX genes was modeled based on Ks of duplication blocks (Figure 6). The duplicated SPX genes in SPX, EXS, MFS, and RING were classified into 3, 2, 2, and 1 groups, respectively. GmSPX-A firstly generated three copies after the Gamma WGT event, followed by loss of one copy. The two retained copies were further doubled after Legume WGD event, and after losing one copy, the rest three copies duplicated after Glycine WGD event, resulting in genes, GmSPX8, GmSPX7, GmSPX3, GmSPX4, and GmSPX2. GmSPX3 lost its

409 linked duplicated gene (Figure 6). Unexpectedly, all three generated copies of GmSPX-EXS-A in 410 Gamma WGT event were retained but their duplicated genes after Legume WGD were lost. 411 Therefore, Glycine WGD resulted in generation of five genes (GmSPX-PHO1;10, GmSPX412 PHO1;5, GmSPX-PHO1;3, GmSPX-PHO1;9, and GmSPX-PHO1;6) after a loss of one of the 413 linked genes. However, GmSPX-EXS-B lost one copy in the first and second round of duplication 414 events and lastly generated six genes (GmSPX-PHO1;1, GmSPX-PHO1;4, GmSPX-PHO1;14, $415 \mathrm{GmSPX}-\mathrm{PHO}$;;8, GmSPX-PHO1;7, GmSPX-PHO1;2). GmSPX-B and $-\mathrm{C}$ as well as GmSPX$416 \quad M F S-B$ shared the same evolutionary trajectory and generated two duplicated genes in the same 417 way after three rounds of the evolution processes. In addition, GmSPX-MFS-A and GmSPX-RING 418 were somewhat similar as both produced two duplicated blocks, although one copy was lost in 


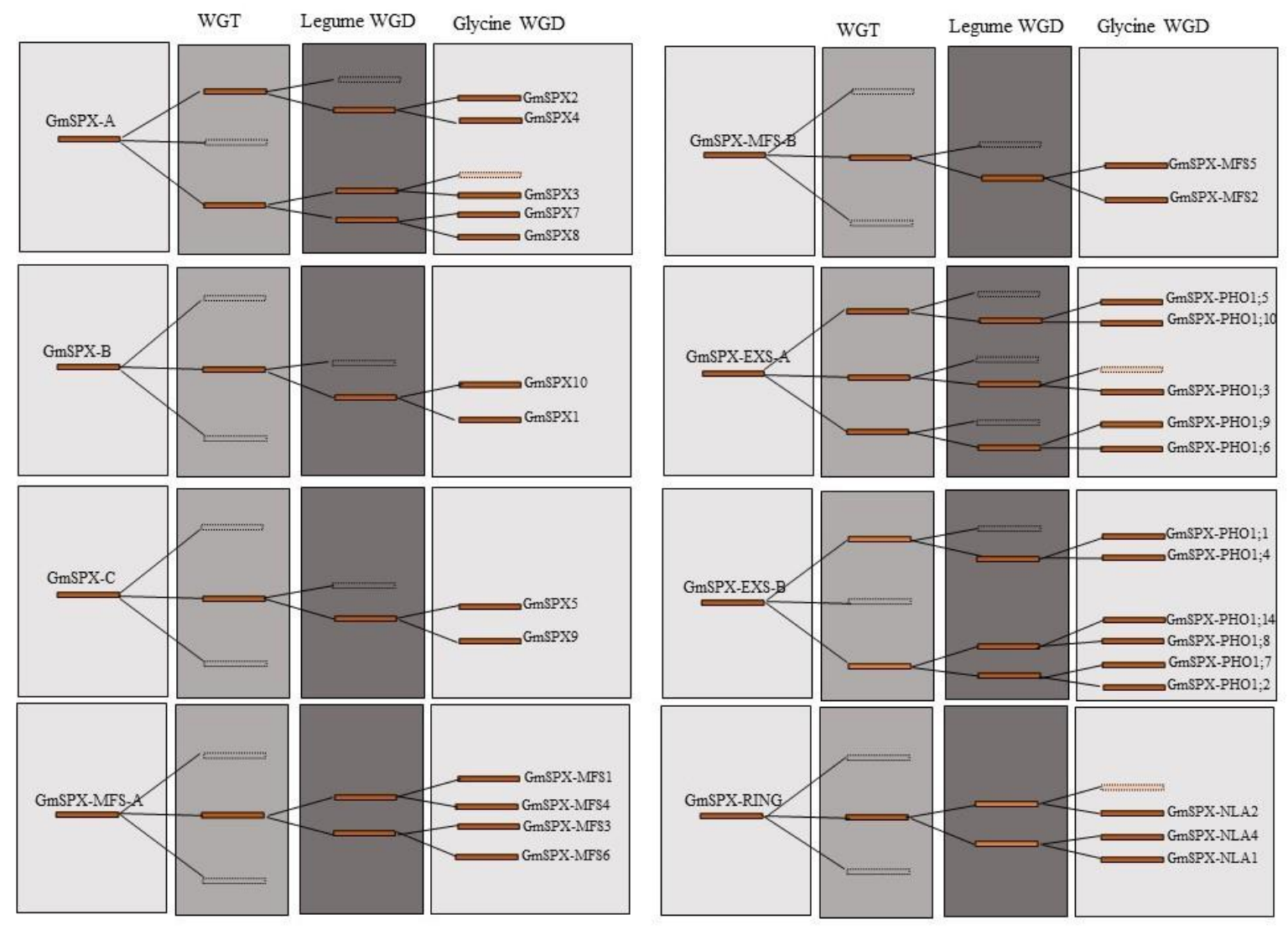

Figure 6. The evolutionary history of GmSPX genes. The reserved and lost blocks in the corresponding evolution are displayed by

\section{Functional characterization of orthologous genes in legumes}

427 Orthologs and orthogroups among seven current angiosperms were determined with OrthoFinder.

428 Altogether, from 218 genes, 216 genes could be classified in seven orthogroups and just two genes

429 of rapeseed (BnaA6.PHO1;H3c and BnaA9.PHO1;H3b) were not grouped, maybe suggesting a

430 brassica-specific function for these proteins. All members of SPX, SPX-MFS, and SPX-RING

431 were assigned into one group; 1, 3, and 4, respectively. On the other hand, members of EXS family

432 were divided into four distinct groups: group 2 that was dicot-specific; group 7, brassicaceae- 
433 specific; as well as groups 5 and 6 that contained genes from all species (Table 2). All genes in an

434 orthogroup are descended from a single ancestral gene.

435 Table 2. Ortholog groups among soybean, common bean, Medicago, Arabidopsis, rice, wheat, and brassica.

\begin{tabular}{lllllllllll}
\hline Orthogroup & $\mathrm{Pv}$ & $\mathrm{Gm}$ & Ath & Bna & $\mathrm{Os}$ & $\mathrm{Ta}$ & $\mathrm{Mt}$ & Total & \\
\hline 1 & & & & & & & & & \\
2 & 4 & 10 & 4 & 11 & 5 & 15 & 5 & 54 & SPX group \\
3 & 4 & 8 & 8 & 29 & 0 & 0 & 4 & 53 & SPX.EXS dicot-specific group \\
4 & 3 & 6 & 3 & 8 & 4 & 12 & 3 & 39 & SPX.MFS group \\
5 & 3 & 4 & 2 & 7 & 2 & 7 & 4 & 29 & SPX.RING group \\
6 & 2 & 4 & 1 & 4 & 1 & 9 & 2 & 23 & SPX.EXS group \\
7 & 1 & 2 & 1 & 5 & 2 & 3 & 1 & 15 & SPX.EXS group \\
& 0 & 0 & 1 & 2 & 0 & 0 & 0 & 3 & SPX.EXS brassicaceae-specific group
\end{tabular}

437 Orthologous genes across Arabidopsis and the three legume crops are presented in Table 3. Some 438 genes showed a simple one-to-one orthology relationship, such as GmSPX6, $P v S P X 2$, and MtSPX5 439 with AtSPX4; GmPHO1;3, PvPHO1;1, and MtPHO1;4 with AtPHO1;H10; and GmNLA3, $440 \quad P v N L A 1$, and MtNLA2 with AtNLA2. Others showed one-to-many and many-to-many orthology 441 relationships. Interestingly, the pattern of AtSPXs orthology relationships were the same among 442 three legumes, and each SPX gene has the same evolutionary trajectories. To overcome the 443 difficulty of one-to-many and many-to-many orthology inference, expressologs of AtSPXs with 444 soybean and Medicago were retrieved from the Expression Tree Viewer [32]. Expression Tree 445 Viewer allows to visualize expressologs depending on both sequence similarity and expression 
447 Table 3. Ortholog genes between legumes and Arabidopsis.

\begin{tabular}{|c|c|c|c|}
\hline Arabidopsis & Soybean & Common bean & Medicago \\
\hline AtSPX1/2 & GmSPX3/7/8 & PvSPX1/5 & MtSPX4 \\
\hline AtSPX3 & GmSPX1/10 & - & MtSPX3 \\
\hline AtSPX4 & GmSPX6 & PvSPX2 & MtSPX5 \\
\hline AtPHO1 & GmPHO1;2/7/8/14 & PvPHO1;6/5 & MtPHO1;1/2 \\
\hline AtPHO1; $\mathrm{H} 1$ & GmPHO1;1/4 & PvPHO1;4 & MtPHO1;7 \\
\hline AtPHO1;H2/3/4/5/7/8 & GmPHO1;5/10/11/12/13 & PvPHO1;2/3 & - \\
\hline AtPHO1; H9 & GmPHO1;6/9 & PvPHO1;7 & MtPHO1;3/5/6 \\
\hline AtPHO1;H10 & GmPHO1;3 & PvPHO1;1 & MtPHO1;4 \\
\hline AtMFS1/2/3 & GmMFS1/2/3/4/5/6 & PVMFS1/2/3 & MtMFS1/2/3 \\
\hline AtNLA/AtBAH1 & GmNLA1/2/4 & PVNLA2/3 & MtNLA1/3/4 \\
\hline AtNLA2 & GmNLA3 & PvNLA1 & MtNLA2 \\
\hline
\end{tabular}

449 pattern similarity. Implementing this web tool resulted in postulating expressologs between 450 Arabidopsis and soybean and Medicago (Supplemental Table S6). Generally, the results were in 451 very good agreement with previous results from phylogenetic tree and OrthoFinder. Based on the 452 Expression Tree Viewer results, we could designate GmPHO1;2/7 and MtPHO1;1/2 as the 453 functional orthologs of $\mathrm{AtPHOI}$ and $\mathrm{AtPHO1} ; \mathrm{Hl}$ with the function of long-distance Pi transport. 454 However, it was difficult to find expressologs for other SPXs. Consistently, the function of 
GmSPX1 [31] and GmSPX3 [29] were characterized with negative and positive regulatory roles in phosphate deficiency that are the same for AtSPX1/2 and AtSPX3 [6].

457 Expression analysis of SPXs in Arabidopsis and soybean

SPX genes are involved in various physiological process but they are specifically known for their role in phosphate signaling and phosphate homeostasis. To get insight into the potential developmental roles and preferential tissue expression, we analyzed a raw RNA-seq dataset from different developmental stages of different soybean tissues (PRJNA238493). We profiled the

462 GmSPXs expression across 17 different samples (Additional file 1: Figure S13). Overall, we 463 observed different expression patterns of GmSPXs in various developmental stages of different 464 tissues, indicating a functional divergence in each class of GmSPXs [27, 44]. For example, GmMFS2/5 and GmPHO1;2/7 showed the same expression in almost all samples but were 466 preferentially expressed in leaf and root, respectively. It can be concluded that they are not 467 involved in the developmental processes. On the other hand, duplicated gene pairs arising from 468 Glycine-specific WGD showed very similar expression patterns across all the samples, especially 469 the GmMFS2/5 gene pair, but except GmSPX5/9 and GmPHO1;5/10 pairs. Taking together, both 470 groups of duplicated genes with the same or different expression pattern showed the evidence of 471 sub-functionalization during the soybean evolution [44].

472 In order to gain insight how individual SPX genes are regulated by Pi deficiency, we analysed 473 publicly available RNAseq dataset (PRJNA544698) [45] and used DPGP software to cluster genes 474 with similar response patterns. DPGP clustering revealed 6 and 4 clusters for root (Additional file 475 1: Figure S14) and leaf (Additional file 1: Figure S15), respectively. We designated names for 476 each cluster based on their patterns; up-reg-fast (cluster 3 in root and cluster 1 in leaf), down-reg477 fast (cluster 2 in root and cluster 3 in leaf), the lowest-peak-T1 (cluster 6 in root), the lowest-peak- 
478 T2 (cluster 5 in root), the highest-peak-T1 (cluster 1 in root), up-reg-slow (cluster 4 in leaf), and

479 the highest-peak-T2 (cluster 4 in root and cluster 2 in leaf). As can be seen in the Table 4, some

480 genes have opposite pattern of regulation in different tissues. To exemplify, GmSPX1 was placed

481 in down-reg-fast in root and up-reg-fast in leaf, GmSPX-PHO1;10 is found in the highest-peak-T1

482 in root and the highest-peak-T2 in the leaf, while GmSPX6, GmSPX-NLA1, and GmSPX-NLA3

483 were in the lowest-peak-T2 cluster in root and the highest-peak-T2 in leaf. The homologs of

$484 \mathrm{AtPHO}$ and $\mathrm{AtPHO} 1 ; \mathrm{H1}(\mathrm{PHO} 1 ; 2 / 7 / 14)$ showed an up-reg-fast pattern of cluster 4 in root and the

485 highest-pick-T2 in clusters 2 leaf. Supporting these patterns, He et al. (2013) reported similar

expression pattern for these genes, however, there is no clear association between increasing mRNA level of these genes in leaves during phosphate deficiency and growth or shoot Pi content [15]. Overall, for the genes which show tissue-specific expression, we observed different patterns in root and shoot in response to phosphate deficiency.

490 Finally, after investigating developmental and dynamical expression patterns of GmSPX, we used another RNA-seq dataset from Arabidopsis and soybean to examine the expression of $S P X s$ in three different zones of root [46]. The original data were generated in multiple species, however, we only used RPKM values from Arabidopsis and soybean. A general comparison showed that

494 almost all SPX tended to group species-based rather than orthology-based, except AtPHO1 and 495 AtPHO1;H1 which clustered with their orthologs, GmPHO1;2 and GmPHO1;7 (Additional file 1:

496 Figure S16). Thus, we can conclude that the tissue-specific genes pose difficulty to identify 497 functional orthologs because of probable tissue inequivalences among species. 
Table 4. Different patterns of clusters in root and leaf in the time series dataset of soybean.

\begin{tabular}{lll}
\hline Patterns & Root clusters clusters
\end{tabular}

up-reg-fast

down-reg-fast

up-reg-slow

highest-peak-T1

highest-peak-T2

lowest-peak-T1

lowest-peak-T2
Cluster3: $S P X 4, S P X . P H O 1 ; 2$,

SPX.PHO1;7, SPX.PHO1;8, SPX.PHO1;14,

SPX.PHO1;6

Cluster2: $S P X 1, S P X 10, S P X 5, S P X . M F S 4$,

SPX.NLA2, SPX.NLA4, SPX.PHO1;12

Cluster1: $S P X . M F S 1, S P X . P H O 1 ; 5$,

SPX.PHO1;10, SPX.PHO1;9, SPX.PHO1;1

Cluster4: SPX.MFS5, SPX.PHO1;4,

SPX.PHO1;11

Cluster6: $S P X 3, S P X 7, S P X 8, S P X . M F S 2$,

SPX.MFS6

Cluster5: SPX6, SPX.NLA1, SPX.NLA3
Cluster1: $S P X 1, S P X . M F S 6$,

MFS-NLA2, MFS-NLA4,

SPX.PHO1;11

Cluster3: $S P X 2, S P X . M F S 2$,

SPX.MFS5, SPX.MFS4

Cluster4: $S P X 4, S P X 5$,

SPX.PHO1;1, SPX.PHO1;4,

SPX.PHO1;6, SPX.PHO1;9

Cluster2: $S P X 3, S P X 6, S P X 7$,

SPX8, SPX10, SPX.NLA1,

SPX.NLA3, SPX.PHO1;2,

SPX.PHO1;7, SPX.PHO1;14,

SPX.PHO1;5, SPX.PHO1;10,

SPX.PHO1;12

501 


\section{Discussion}

The role of SPX domain-containing proteins in Pi homeostasis in Arabidopsis, rice, rapeseed, and

wheat and to some extent in soybean and common bean were studied previously [3, 13, 27, 29-31,

35]. While an evolutionary analysis of SPX-EXS [47] and SPX-MFS [24] classes has been

512 knowledge gap, we performed a comprehensive search for SPX genes throughout three legume 513 crops, including soybean, M. truncatula, and common bean and also algae, liverwort, hornwort,

514 and basal angiosperms to figure out how this gene family originated and expanded during the

515 evolution as well as to identify SPX functional orthologs in legumes.

\section{Evolutionary conservation and divergence of SPX gene family from algae to legumes}

517 Proteins harboring SPX domain has been reported to form four classes based on their domains.

518 Meanwhile, some other classes have been revealed in the basal plants and algae such as SPX-SLC and SPX-VTC [24]. Here we report other functional protein domains being fused to SPX domains,

520 including EIN3, S6PP, EIN3-S6PP, and Kelch in S. moellendorffii, CitMHS in C. crispus,

521 Na_sulph_symp in G. sulphuraria and C. reinhardtii, BET (Bromodomain extra-terminal-

522 transcription regulation) in P. somniferum, EXS.rve in C. braunii, and Sugar_tr in M. polymorpha.

523 Interestingly, some of these new domains have been lost in the land plants and all of them in 524 angiosperms. Domains present in algae before land colonization probably had specific functions 525 that are not required for land plants. For example, SPX-SLC and SPX-VTC were reported in algae 
that store polyP and are thus lost in plants with Pi vacuole storage, which in turn gained SPX-MFS [24]. Among all assayed species, S. moellendorffii showed the most variation of SPX genes, which could be due to its special ability of resurrection. Moreover, unlike other SPX proteins, SPX domain are located at C terminal in S6PP-SPX, EIN3-S6PP_C-SPX, EIN3-SPX, and Kelch-SPX classes. The function of other fusion proteins is unknown so far. Particularly interesting are the fusions of SPX with EIN3 domains, because in Arabidopsis EIN3 is directly involved in regulation of phosphate homeostasis through binding to promoter of PHRI [48]. The SPX domain would then add another level of control for this interaction and allow the reciprocal regulation of ethylene signaling by phosphate. Similarly, Kelch domains are often found in regulatory proteins, for example fused to F-Box proteins [49], hence, again, the fusion with SPX may connect multiple regulatory circuits. If the SPX domain enables the activities of the additional domains to be modulated by phosphate (or InsPP), this offers an intriguing opportunity for using these domains in synthetic biology approaches to make various cellular processes controlled by phosphate. These hypotheses, however, have to be verified. On the other hand, RING and MFS classes have gradually appeared in the later-diverging plants. MFS and then RING class have the least fluctuations from 1 to 6 genes. In contrast, EXS class had high variation of gene numbers in each species and also the highest number of identified genes in comparison with the other classes. Also, presence of this domain in whole Eukarya except algae, suggest that it has been lost in some algae.

The number of whole-genome duplications is correlated with gene family size $[47,50]$, which is consistent with our results, since $P$. somniferum and $G$. max with two WGD events had the largest sizes of SPX family $[51,52]$. The expansion of SPX family in these two plants is mostly affected by WGD duplication type, while segmental/local duplication type was the main contributor of expansion in S. moellendorffii, the species with third greatest SPX family, which might explain its 
unique classes. Algae possess 2 to 5 SPX gene family members. The expansion in P. patens (22 members), could suggest that duplications took place after plant terrestrialization as the SPX

551 proteins became more important [53].

552 The phylogenetic analysis brought some unexpected findings. First, it showed three clades for 4 553 subfamilies; SPX and EXS in two different clades, but MFS and RING classes diverged from the 554 same ancestor. Second, SPXs from algae did not group with other species in any clade, except of SPX-I. It can be concluded that genes in the SPX-I sub-clade are the most ancient genes in angiosperms that were diverged from the same ancestor with green algae. Hence, AtSPX4, $557 G m S P X 6, M t S P X 5, P v S P X 2$, and $O s S P X 4$ probably have the same function with their ancestral 558 orthologs in the green algae, but the genes in two other sub-clades, SPX-II and SPX-III have evolved after divergence of streptophytes and chlorophytes and might have acquired additional functions. AtSPX4 and OsSPX4 have indeed the same function and mechanism in regulation of 561 PSI, as in presence of phosphate both proteins interact in the cytosol with the corresponding key regulators AtPHR1 and OsPHR2, and prevent them from translocating to nucleus $[11,54]$. During

563 P deficiency they are rapidly degraded, releasing thus the PHR factors to induce transcription of 564 PSI genes. The two proteins however, also differ, as while OsSPX4 integrates nitrate and 565 phosphate signaling, AtSPX4 does not seem to have this function, but on the other hand integrates 566 phosphate signaling and anthocyanin biosynthesis $[11,55]$.

567 The MFS class as the most recently diverged class of SPX proteins was divided into two sub568 clades, with MFS-I specifically containing monocots, suggesting that MFS genes in monocots 569 diversified differently in comparison with basal angiosperms and eudicots. This may be due to 570 different $\mathrm{Pi}$ storage between monocots and eudicots [6, 56, 57]. While monocots store $\mathrm{P}$ 571 preferentially in the roots and their leaves have the highest $\mathrm{P}$ concentration in the mesophyll cells, 
572 eudicots store much more $\mathrm{P}$ in the leaves with the highest concentration in the epidermis [56]. It

573 is thus possible that the different cellular localization drove a different evolution of SPX-MFS

574 genes between monocots and dicots. Modern RING class genes have evolved two times, RING-I

575 clade arose from a duplication of the common ancestor of mosses and angiosperms and RING-II

576 arose from duplication of the common ancestor of lycophytes, liverwort and angiosperms. In the

577 EXS class, EXS-III clade did not contain any orthologs from monocots but interestingly, many

578 AtPHOl genes such as AtPHO1; $H 2 / 3 / 4 / 5 / 6 / 7 / 8$ grouped specifically with the genes from Brassica

579 napus, suggesting special functions in Brassicaceae. Only AtPHO1;H9 and AtPHO1;H1O had two

580 and one orthologs in the legumes, respectively.

581 Based on collinearity analyses, species with more WGD events showed more inter-species

582 collinearity, but S. moellendorffii with locally expanded SPX and rice with mostly dispersed

583 expanded SPX just showed intra-genome collinearity. Low collinear relationship between rice and

584 eudicots was reported previously [58] and explained by longer evolutionary distance and more

585 genome rearrangements [59] as well as the erosion of macrosynteny between monocots and dicots

586 [60]. Our results are consistent with the monocot paleopolyploidy after their divergence from

587 eudicots [58]. Having collinear relationship can arise from paleopolyploidy in the common

588 ancestor, but $S$. moellendorffii has no evidence for WGD events and its intra-genome collinear

589 blocks arose from segmental/local duplication [37].

590 Functional characterization of SPXs in legumes

591 Due to the functional conservation of proteins across species, determination of orthologous

592 relationships can provide useful insights about the biological role of these proteins [61]. As plants

593 have undergone various duplication events and had different evolutionary trajectories, relating

594 same functions to the orthologs are difficult, especially there are one-to-many or many-to-many 
orthologous relationships [32]. Therefore, two different methods, phylogenetic inference of orthologs from protein sequences and expressolog identification, were conducted for prediction of functional orthologs of SPXs. This was necessary because, firstly, there are complex orthology relationships among some SPX genes that prevented Orthofinder to detect the exact functional identify expressologs, due to difficulties in assignment of tissue equivalencies between legumes most of GmSPXs except for homologs of AtPHOl and AtPHO1;H1. Taking together, we could assign functions of AtSPX4, AtPHO1;H1O and AtNLA2 to their predicted orthologs from Orthofinder and AtPHOl and AtPHOl;H1 to their orthologs from expressolog identification results. To examine this conclusion, we analyzed two different datasets of soybean to profile $G m S P X$ s expression in different tissues and developmental stages as well as their dynamic 607 expression responses to Pi deficiency in leaf and root. Overall, we found that almost all GmSPXs samples as well as in root and leaf responses to the dynamic Pi deficiency. In summary, these transcriptome analyses highlighted that GmSPX genes might be involved in different

611 developmental processes and stresses beyond phosphate starvation response. It is probable that 612 new or sub-functionalization in soybean and generally in legumes took place with the new 613 functions of SPX proteins waiting to be discovered. Our analyses lay a solid foundation for the 614 future functional studies of SPX proteins from algae to legumes.

\section{Conclusion}


618

619

620

621

622

623

624

625

626

627

628

629

630

631

632

633

634

635

636

637

638

639

and collinear gene blocks during evolution from algae to angiosperms. Afterwards, focusing on legumes, we tried to model evolutionary history of SPXs in soybean and identify functional orthologs. We could predict the putative SPX proteins involved in long-distance Pi transportation in soybean and Medicago. Our study not only provides a global view of the evolution and expansion of SPX gene family in important species but also provides the first step for more detailed investigations of the functions of individual $S P X s$ in legumes.

\section{Material and methods}

\section{Bioinformatic identification of SPX proteins}

In order to identify SPX domain-containing proteins in our species; legume crops (soybean Glycine max, alfalfa - Medicago truncatula, and common bean - Phaseolus vulgaris), mosses (Physcomitrella patens), liverwort (Marchantia polymorpha), Rhodophytes (Cyanidioschyzon merolae, Galdieria sulphuraria, and Chondrus crispus), chlorophytes (Chlamydomonas reinhardtii and Ostreococcus lucimarinus), charophytes (Chara braunii), basal angiosperms (Papaver somniferum, Amborella trichopoda, and Nymphaea colorata), and lycophytes (Selaginella moellendorffii), full-length protein sequences of AtSPXs were used for BLASTP searches across proteomes of the above mentioned species. After removing redundant sequences, the SPX proteins obtained through BLASTP search were investigated for the presence of additional domains along with SPX domain using SMART [62], Pfam [63], Conserved Domain Database (CDD) [64], and PROSITE [65] databases.

The sequences of identified SPX proteins in the three legume crops were analyzed for their physiochemical properties; including isoelectric point $(\mathrm{pI})$, molecular weight $(\mathrm{Mw})$, instability index (II), grand average of hydropathicity (GRAVY), and aliphatic index (AI) using ProtParam 
640 tool of ExPASy website (https://web.expasy.org/protparam/). Subcellular location prediction was

641 conducted using Wolf Psort [66].

642 Phylogeny analysis and identification of conserved motifs

643 The amino acid sequences of identified SPX proteins in our surveyed species and Arabidopsis as

644 reviewed in [6], rice [6], wheat [3], and Brassica napus [27] were downloaded from EnsemblPlants

645 (https://plants.ensembl.org/index.html). Three sequences to be used as outgroup, XPR1 from

646 human and mouse, and SYG1 from C. elegans, were downloaded from NCBI database

647 (https://www.ncbi.nlm.nih.gov/). Multiple sequence alignment of these full-length sequences was

648 performed by ClustalX (ver. 2.1; http://www.clustal.org/). Then, we used Maximum Likelihood

649 method and JTT matrix-based model in MEGA 7 software to build a phylogenetic tree from the

650 sequence alignment using following parameters: p-distance model, partial deletion and 1000

651 bootstraps. To predict conserved motifs of SPX proteins across all species, as well as Arabidopsis

652 and rice, MEME (http://meme-suite.org/tools/meme) tool with the maximum number of motifs 20

653 was used. Logo sequences of conserved motifs were obtained by Weblogo 3

654 (http://weblogo.threeplusone.com/).

655 Collinearity analysis and gene expansion pattern of SPX from algae to eudicots

656 In order to get insight about how collinear blocks have been conserved during the evolution, we

657 performed collinearity analysis three times with different species; 1 . Among three legume crops,

658 Arabidopsis, rice, P. somniferum, and N. colorota, 2. Among S. moellendorffii, P. patens, N.

659 colorata, and A. trichopoda, and 3. Among three legume crops using MCScanX toolkit [67] to get

660 collinear gene blocks and also duplication types by duplicate_gene_classifier program. To

661 visualize the collinear blocks among the first and third runs, tbtools was used [68]. Because of 
662

663

664

665

666

667

668

669

670

671

672

673

674

675

676

677

678

679

680

681

682

non-chromosomal reference genomes in $P$. patens and $S$. moellendorffii we just retrieved their collinear gene blocks without visualization.

\section{Selective pressure and evolutionary models of SPX genes in the legume crops}

Duplication blocks between each two species of soybean, common bean and M. truncatula were retrieved from the Plant Genome Duplication Database (PGDD, http://chibba.agtec.uga.edu/duplication/). SPX gene blocks were manually extracted and used for further analyses. The selective pressure on duplicated genes were estimated by retrieving synonymous (Ks) and non-synonymous (Ka) per site between the duplicated gene-pairs using from PGDD database. The Ka/Ks ratio was assessed to determine the molecular evolutionary rates of each gene pair. Generally, the $\mathrm{Ka} / \mathrm{Ks}<1$ indicates purifying selection, $\mathrm{Ka} / \mathrm{Ks}>1$ indicates positive selection, and $\mathrm{Ka} / \mathrm{Ks}=1$ indicates neutral selection. The divergence time of the duplication blocks was evaluated to investigate the evolution of GmSPX genes. If the Ks $>1.5$, the divergence time is after the Gamma whole-genome triplication (WGT); if the $\mathrm{Ks}<0.3$, the divergence time is after the Glycine whole-genome duplication (WGD) event; and when the Ks is between 0.3 and 1.5, the divergence time is after legume WGD event but before the Glycine WGD event [69, 70].

\section{Identification of Cis-acting-elements in the promoters of SPX gene family}

For finding evolutionary pattern of Cis-acting-elements from algae to eudicots, $1500 \mathrm{bp}$ upstream from the start codon of SPX genes in all assayed species and Arabidopsis were downloaded from the EnsemblPlants and analyzed using the PlantCARE database (http://bioinformatics.psb.ugent.be/webtools/plantcare/html/). Afterwards, SPX genes were clustered with hierarchical clustering on principal components (HCPC) method by FactMineR 
683 package. All detected cis-acting elements were merged into one matrix with 1 and 0 values for present or absent elements in each promoter, respectively.

\section{Prediction of functional orthologs of AtSPXs across legumes}

To identify functional orthologs in the three legumes, we used OrthFinder to compare SPX genes

687 among 7 species (rice, wheat, rapeseed, Arabidopsis, M. truncatula, soybean, and common bean), weakness of sequence-based ortholog identification for one-to-many and many-to-many orthologs,

expressolog identification among Arabidopsis, soybean, and Medicago

691 (http://bar.utoronto.ca/expressolog_treeviewer/cgi-bin/expressolog_treeviewer.cgi), was used.

\section{Expression analysis of SPX genes}

Three different expression analyses were performed as follows:

1. To compare tissue and developmental expression pattern of GmSPXs, RNA-seq data of 17 samples from different tissues (flower, root, shoot meristem, seed, and leaves) in five developmental stages (germination, trefoil, flowering, seed development, and plant senescence) (PRJNA238493) [72] were analyzed. The gene expression profiles were

2. To visualize changes in $G m S P X$ gene expression in response to $\mathrm{P}$ deficiency we used publicly available dataset (PRJNA544698) [45]. The data were reanalyzed and TPM (Transcript Per Million) values were calculated from samples over different time points of Pi deficiency, including early stress (T, $24 \mathrm{~h}$ ), recovery (TC, $24 \mathrm{~h}$ deficiency, $48 \mathrm{~h}$ resupply), and repeated stress (TCT, additional $24 \mathrm{~h}$ deficiency) in root and leaf tissues. 
The data were clustered using the Dirichlet process with Gaussian process mixture model (DPGP) [73].

3. To assess if the predicted functional orthologs in Arabidopsis and soybean show the same expression in different root development zones, including meristemic zone (MZ), elongation zone (EZ), and differentiation zone (DZ) data from [46] have been used. RPKM values for the SPXs were collected (GSE64665), and $\log 2(\mathrm{RPKM}+1)$ was used to construct correlation heatmap using the pheatmap package (https://www.r-project.org/).

\section{Declarations}

\section{Ethics approval and consent to participate}

713 Not applicable

\section{Consent for publication}

715 Not applicable

716 Availability of data and materials

717 The datasets generated and/or analyzed during the current study are included in the supplemental

718 material.

\section{Competing interests}

720 The authors declare no competing interests

\section{$721 \quad$ Funding}

722 Research in SK's lab is funded by the Deutsche Forschungsgemeinschaft (DFG) under Germany's

723 Excellence Strategy - EXC 2048/1 - project 390686111. 


\section{Authors' contributions}

725 MNC, AN, EE, and SK designed the study. MNC performed the analyses. Assisted with

726 interpretation. MNC wrote the manuscript. All authors reviewed the manuscript. The authors read

727 and approved the final manuscript.

\section{Acknowledgements}

729 We acknowledge the Ministry of Science, Research and Technology of Iran and the University of

730 Shiraz for the exchange scholarship to University of Cologne

731 Abbreviations

732 PHR: Phosphate starvation Response

733 PP-InsPs: inositol pyrophosphates

734 MFS: Major Facilitator Superfamily

735 RING: Really Interesting New Gene

736 NLA: Nitrogen Limitation Adaptation

737 PSI: Pi starvation-induced

738 Ein3: Ethylene intensive 3

739 VTC: vacuolar transporter chaperone

740 CitMHS: Citrate transporter

741 Na_sulph_symp: sodium sulphate symporter

742 S6PP_C: Sucrose-6F-phosphate phosphohydrolase C-terminal

743 Kelch: Galactose oxidase

744 rve: Integrase core domain

745 GRAVY: grand average of hydropathicity

746 LSC: Lysine Surface Cluster

747 Gm: Glycine max

748 Mt: Medicago truncatula 
Pv: Phaseolus vulgaris

Ps: Papaver sumniferum

751

Nc: N. colorota

At: Arabidopsis thaliana

Os: Oryza sativa

CRE: cis-acting elements

MeJA: methyl jasmonate

DPGP: Dirichlet process with Gaussian process mixture model

HCPC: hierarchical clustering on principal components

\section{References}

1. Richardson AE. Regulating the phosphorus nutrition of plants: molecular biology meeting agronomic needs. Plant and soil. 2009;322(1-2):17-24.

761 2. Poirier Y, Bucher M. Phosphate transport and homeostasis in Arabidopsis. The Arabidopsis book/American Society of Plant Biologists. 2002;1. identification, characterization, and expression profiling of SPX gene family in wheat. International journal of biological macromolecules. 2019;140:17-32.

766 4. Balyan HS, Gahlaut V, Kumar A, Jaiswal V, Dhariwal R, Tyagi S, et al. Nitrogen and phosphorus use efficiencies in wheat: physiology, phenotyping, genetics, and breeding. Plant breeding reviews. 2016;40:167-234.

5. Misson J, Raghothama KG, Jain A, Jouhet J, Block MA, Bligny R, et al. A genome-wide transcriptional analysis using Arabidopsis thaliana Affymetrix gene chips determined plant responses to phosphate deprivation. Proceedings of the National Academy of Sciences. 2005;102(33):11934-9.

6. Secco D, Wang C, Arpat BA, Wang Z, Poirier Y, Tyerman SD, et al. The emerging importance of the SPX domain-containing proteins in phosphate homeostasis. New Phytologist. 2012;193(4):842-51.

7. Lv Q, Zhong Y, Wang Y, Wang Z, Zhang L, Shi J, et al. SPX4 negatively regulates phosphate signaling and homeostasis through its interaction with PHR2 in rice. The Plant Cell. 2014;26(4):1586-97.

8. Puga MI, Mateos I, Charukesi R, Wang Z, Franco-Zorrilla JM, de Lorenzo L, et al. SPX1 is a phosphate-dependent inhibitor of Phosphate Starvation Response 1 in Arabidopsis. Proceedings of the National Academy of Sciences. 2014;111(41):14947-52.

9. Wild R, Gerasimaite R, Jung J-Y, Truffault V, Pavlovic I, Schmidt A, et al. Control of eukaryotic phosphate homeostasis by inositol polyphosphate sensor domains. Science. 2016;352(6288):986-90.

10. Jung J-Y, Ried MK, Hothorn M, Poirier Y. Control of plant phosphate homeostasis by inositol pyrophosphates and the SPX domain. Current opinion in biotechnology. 2018;49:156-62.

11. Hu B, Jiang Z, Wang W, Qiu Y, Zhang Z, Liu Y, et al. Nitrate-NRT1. 1B-SPX4 cascade integrates nitrogen and phosphorus signalling networks in plants. Nature plants. 2019;5(4):401.

785 12. Wang Z, Hu H, Huang H, Duan K, Wu Z, Wu P. Regulation of OsSPX1 and OsSPX3 on expression 786 of OsSPX domain genes and Pi-starvation signaling in rice. Journal of Integrative Plant Biology. 787 2009;51(7):663-74.

788 13. Duan K, Yi K, Dang L, Huang H, Wu W, Wu P. Characterization of a sub-family of Arabidopsis 789 genes with the SPX domain reveals their diverse functions in plant tolerance to phosphorus starvation. The 790 Plant Journal. 2008;54(6):965-75. 
14. Hamburger D, Rezzonico E, Petétot JM-C, Somerville C, Poirier Y. Identification and characterization of the Arabidopsis PHO1 gene involved in phosphate loading to the xylem. The Plant Cell. 2002;14(4):889-902.

15. Stefanovic A, Ribot C, Rouached H, Wang Y, Chong J, Belbahri L, et al. Members of the PHO1 gene family show limited functional redundancy in phosphate transfer to the shoot, and are regulated by phosphate deficiency via distinct pathways. The Plant Journal. 2007;50(6):982-94.

16. Kang X, Ni M. Arabidopsis SHORT HYPOCOTYL UNDER BLUE1 contains SPX and EXS domains and acts in cryptochrome signaling. The Plant Cell. 2006;18(4):921-34.

17. Zhou Y, Ni M. SHB1 plays dual roles in photoperiodic and autonomous flowering. Developmental biology. 2009;331(1):50-7.

18. Zhou Y, Zhang X, Kang X, Zhao X, Zhang X, Ni M. SHORT HYPOCOTYL UNDER BLUE1 associates with MINISEED3 and HAIKU2 promoters in vivo to regulate Arabidopsis seed development. The Plant Cell. 2009;21(1):106-17.

19. Zhou Y, Ni M. SHORT HYPOCOTYL UNDER BLUE1 truncations and mutations alter its association with a signaling protein complex in Arabidopsis. The Plant Cell. 2010;22(3):703-15.

20. Ribot C, Zimmerli C, Farmer EE, Reymond P, Poirier Y. Induction of the Arabidopsis PHO1; H10 gene by 12-oxo-phytodienoic acid but not jasmonic acid via a CORONATINE INSENSITIVE1-dependent pathway. Plant physiology. 2008;147(2):696-706.

21. Ribot C, Wang Y, Poirier Y. Expression analyses of three members of the AtPHO1 family reveal differential interactions between signaling pathways involved in phosphate deficiency and the responses to auxin, cytokinin, and abscisic acid. Planta. 2008;227(5):1025-36.

22. Lin S-I, Santi C, Jobet E, Lacut E, El Kholti N, Karlowski WM, et al. Complex regulation of two target genes encoding SPX-MFS proteins by rice miR827 in response to phosphate starvation. Plant and Cell Physiology. 2010;51(12):2119-31.

23. Peng M, Hannam C, Gu H, Bi YM, Rothstein SJ. A mutation in NLA, which encodes a RING-type ubiquitin ligase, disrupts the adaptability of Arabidopsis to nitrogen limitation. The Plant Journal. 2007;50(2):320-37.

24. Wang L, Jia X, Zhang Y, Xu L, Menand B, Zhao H, et al. Loss of two families of SPX domaincontaining proteins required for vacuolar polyphosphate accumulation coincides with the transition to phosphate storage in green plants. Molecular Plant. 2021;14(5):838-46.

25. Kopriva S, Chu C. Are we ready to improve phosphorus homeostasis in rice? Journal of experimental botany. 2018;69(15):3515-22.

26. Smýkal P, Coyne CJ, Ambrose MJ, Maxted N, Schaefer H, Blair MW, et al. Legume crops phylogeny and genetic diversity for science and breeding. Critical Reviews in Plant Sciences. 2015;34(13):43-104.

27. Du H, Yang C, Ding G, Shi L, Xu F. Genome-wide identification and characterization of SPX domain-containing members and their responses to phosphate deficiency in Brassica napus. Frontiers in plant science. 2017;8:35.

28. He L, Zhao M, Wang Y, Gai J, He C. Phylogeny, structural evolution and functional diversification of the plant PHOSPHATE1 gene family: a focus on Glycine max. BMC evolutionary biology. 2013;13(1):103.

29. Yao Z, Tian J, Liao H. Comparative characterization of GmSPX members reveals that GmSPX3 is involved in phosphate homeostasis in soybean. Annals of botany. 2014;114(3):477-88.

30. Yao Z-F, Liang C-Y, Zhang Q, Chen Z-J, Xiao B-X, Tian J, et al. SPX1 is an important component in the phosphorus signalling network of common bean regulating root growth and phosphorus homeostasis. Journal of experimental botany. 2014;65(12):3299-310.

31. Zhang J, Zhou X, Xu Y, Yao M, Xie F, Gai J, et al. Soybean SPX1 is an important component of the response to phosphate deficiency for phosphorus homeostasis. Plant Science. 2016;248:82-91.

32. Patel RV, Nahal HK, Breit R, Provart NJ. BAR expressolog identification: expression profile similarity ranking of homologous genes in plant species. The Plant Journal. 2012;71(6):1038-50. 
33. Rouached H, Arpat AB, Poirier Y. Regulation of phosphate starvation responses in plants: signaling players and cross-talks. Molecular plant. 2010;3(2):288-99.

34. Liu N, Shang W, Li C, Jia L, Wang X, Xing G, et al. Evolution of the SPX gene family in plants and its role in the response mechanism to phosphorus stress. Open biology. 2018;8(1):170231.

35. Secco D, Baumann A, Poirier Y. Characterization of the rice PHO1 gene family reveals a key role for OsPHO1; 2 in phosphate homeostasis and the evolution of a distinct clade in dicotyledons. Plant physiology. 2010;152(3):1693-704.

36. Yang J, Zhou J, Zhou H-J, Wang M-M, Liu M-M, Ke Y-Z, et al. Global Survey and Expressions of the Phosphate Transporter Gene Families in Brassica napus and Their Roles in Phosphorus Response. International journal of molecular sciences. 2020;21(5):1752.

37. VanBuren R, Wai CM, Ou S, Pardo J, Bryant D, Jiang N, et al. Extreme haplotype variation in the desiccation-tolerant clubmoss Selaginella lepidophylla. Nature communications. 2018;9(1):1-8.

38. Zhao T, Holmer R, de Bruijn S, Angenent GC, van den Burg HA, Schranz ME. Phylogenomic synteny network analysis of MADS-box transcription factor genes reveals lineage-specific transpositions, ancient tandem duplications, and deep positional conservation. The Plant Cell. 2017;29(6):1278-92.

39. Dewey CN. Positional orthology: putting genomic evolutionary relationships into context. Briefings in bioinformatics. 2011;12(5):401-12.

40. Bokros N, Popescu SC, Popescu GV. Multispecies genome-wide analysis defines the MAP3K gene family in Gossypium hirsutum and reveals conserved family expansions. BMC bioinformatics. 2019;20(2):73-85.

41. Deokar AA, Tar'an B. Genome-wide analysis of the aquaporin gene family in chickpea (Cicer arietinum L.). Frontiers in plant science. 2016;7:1802.

42. Cui L, Feng K, Wang M, Wang M, Deng P, Song W, et al. Genome-wide identification, phylogeny and expression analysis of AP2/ERF transcription factors family in Brachypodium distachyon. BMC genomics. 2016;17(1):636.

43. Lynch M, Conery JS. The evolutionary fate and consequences of duplicate genes. science. 2000;290(5494):1151-5.

44. Zhang Z, Zhao Y, Feng X, Luo Z, Kong S, Zhang C, et al. Genomic, molecular evolution, and expression analysis of NOX genes in soybean (Glycine max). Genomics. 2019;111(4):619-28.

45. O'Rourke JA, McCabe CE, Graham MA. Dynamic gene expression changes in response to micronutrient, macronutrient, and multiple stress exposures in soybean. Functional \& integrative genomics. 2020;20(3):321-41.

46. Huang L, Schiefelbein J. Conserved gene expression programs in developing roots from diverse plants. The Plant Cell. 2015;27(8):2119-32.

47. He L, Zhao M, Wang Y, Gai J, He C. Phylogeny, structural evolution and functional diversification of the plant PHOSPHATE1 gene family: a focus on Glycine max. BMC Evolutionary Biology. 2013;13(1):1-13.

48. Liu Y, Xie Y, Wang H, Ma X, Yao W, Wang H. Light and ethylene coordinately regulate the phosphate starvation response through transcriptional regulation of PHOSPHATE STARVATION RESPONSE1. The Plant Cell. 2017;29(9):2269-84.

49. Sun Y, Zhou X, Ma H. Genome-wide Analysis of Kelch Repeat-containing F-box Family. Journal of Integrative Plant Biology. 2007;49(6):940-52.

50. Flagel LE, Wendel JF. Gene duplication and evolutionary novelty in plants. New Phytologist. 2009;183(3):557-64.

51. Pei L, Wang B, Ye J, Hu X, Fu L, Li K, et al. Genome and transcriptome of Papaver somniferum Chinese landrace CHM indicates that massive genome expansion contributes to high benzylisoquinoline alkaloid biosynthesis. Horticulture Research. 2021;8(1):1-13.

52. Cannon SB, Shoemaker RC. Evolutionary and comparative analyses of the soybean genome. Breeding science. 2012;61(5):437-44. 
53. Jiang M, Chu Z. Comparative analysis of plant MKK gene family reveals novel expansion mechanism of the members and sheds new light on functional conservation. Bmc Genomics. 2018;19(1):118.

54. Osorio MB, Ng S, Berkowitz O, De Clercq I, Mao C, Shou H, et al. SPX4 acts on PHR1-dependent and-independent regulation of shoot phosphorus status in Arabidopsis. Plant physiology. 2019;181(1):33252.

55. He Y, Zhang X, Li L, Sun Z, Li J, Chen X, et al. SPX4 interacts with both PHR1 and PAP1 to regulate critical steps in phosphorus-status-dependent anthocyanin biosynthesis. New Phytologist. 2021;230(1):205-17.

56. Conn S, Gilliham M. Comparative physiology of elemental distributions in plants. Annals of botany. 2010;105(7):1081-102.

57. Conn SJ, Gilliham M, Athman A, Schreiber AW, Baumann U, Moller I, et al. Cell-specific vacuolar calcium storage mediated by CAX1 regulates apoplastic calcium concentration, gas exchange, and plant productivity in Arabidopsis. The Plant Cell. 2011;23(1):240-57.

58. Jiao Y, Li J, Tang H, Paterson AH. Integrated syntenic and phylogenomic analyses reveal an ancient genome duplication in monocots. The Plant Cell. 2014;26(7):2792-802.

59. Tang H, Bowers JE, Wang X, Ming R, Alam M, Paterson AH. Synteny and collinearity in plant genomes. Science. 2008;320(5875):486-8.

60. Abrouk M, Murat F, Pont C, Messing J, Jackson S, Faraut T, et al. Palaeogenomics of plants: synteny-based modelling of extinct ancestors. Trends in plant science. 2010;15(9):479-87.

61. Bishop EH, Kumar R, Luo F, Saski C, Sekhon RS. Genome-wide identification, expression profiling, and network analysis of AT-hook gene family in maize. Genomics. 2020;112(2):1233-44.

62. Letunic I, Doerks T, Bork P. SMART: recent updates, new developments and status in 2015. Nucleic acids research. 2015;43(D1):D257-D60.

63. Bateman A, Coin L, Durbin R, Finn RD, Hollich V, Griffiths-Jones S, et al. The Pfam protein families database. Nucleic acids research. 2004;32(suppl_1):D138-D41.

64. Marchler-Bauer A, Derbyshire MK, Gonzales NR, Lu S, Chitsaz F, Geer LY, et al. CDD: NCBI's conserved domain database. Nucleic acids research. 2015;43(D1):D222-D6.

65. Sigrist CJ, Cerutti L, De Castro E, Langendijk-Genevaux PS, Bulliard V, Bairoch A, et al. PROSITE, a protein domain database for functional characterization and annotation. Nucleic acids research. 2010;38(suppl_1):D161-D6.

66. Horton P, Park K-J, Obayashi T, Fujita N, Harada H, Adams-Collier C, et al. WoLF PSORT: protein localization predictor. Nucleic acids research. 2007;35(suppl_2):W585-W7.

67. Wang Y, Tang H, DeBarry JD, Tan X, Li J, Wang X, et al. MCScanX: a toolkit for detection and evolutionary analysis of gene synteny and collinearity. Nucleic acids research. 2012;40(7):e49-e.

68. Chen C, Chen H, He Y, Xia R. TBtools, a toolkit for biologists integrating various biological data handling tools with a user-friendly interface. BioRxiv. 2018:289660.

69. Li Q, Guo L, Wang H, Zhang Y, Fan C, Shen Y. In silico genome-wide identification and comprehensive characterization of the BES1 gene family in soybean. Heliyon. 2019;5(6):e01868.

70. Severin AJ, Cannon SB, Graham MM, Grant D, Shoemaker RC. Changes in twelve homoeologous genomic regions in soybean following three rounds of polyploidy. The Plant Cell. 2011;23(9):3129-36.

71. Emms DM, Kelly S. OrthoFinder: phylogenetic orthology inference for comparative genomics. Genome biology. 2019;20(1):1-14.

72. Shen Y, Zhou Z, Wang Z, Li W, Fang C, Wu M, et al. Global dissection of alternative splicing in paleopolyploid soybean. The Plant Cell. 2014;26(3):996-1008.

73. McDowell IC, Manandhar D, Vockley CM, Schmid AK, Reddy TE, Engelhardt BE. Clustering gene expression time series data using an infinite Gaussian process mixture model. PLoS computational biology. 2018;14(1):e1005896. 
bioRxiv preprint doi: https://doi.org/10.1101/2021.08.24.457498; this version posted August 24, 2021. The copyright holder for this preprint (which was not certified by peer review) is the author/funder, who has granted bioRxiv a license to display the preprint in perpetuity. It is made available under aCC-BY-NC 4.0 International license.

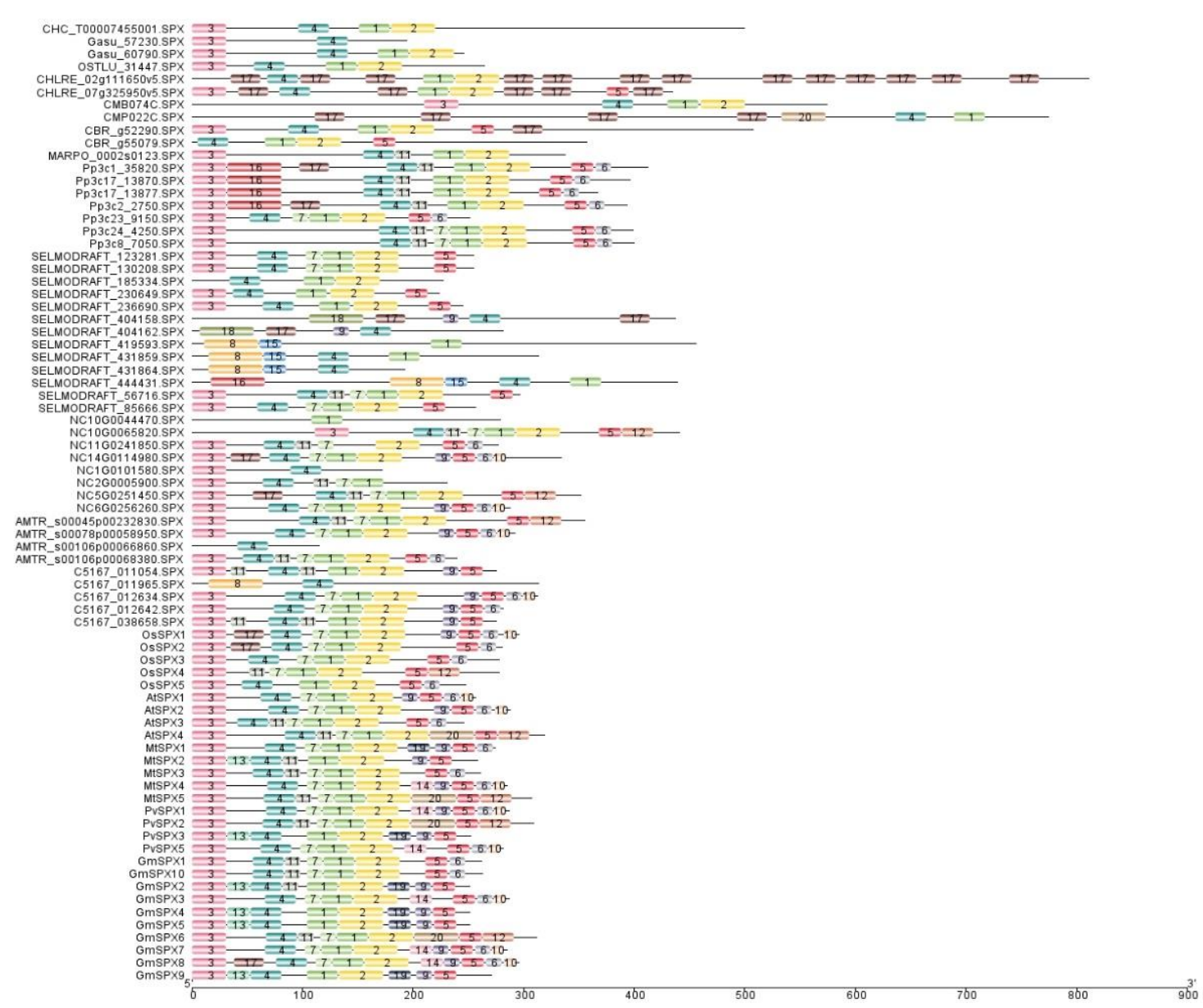

Figure S1. Motif loss and gain in SPX class genes during the evolution from algae to current Angiosperms 
bioRxiv preprint doi: https://doi.org/10.1101/2021.08.24.457498; this version posted August 24, 2021. The copyright holder for this preprint (which was not certified by peer review) is the author/funder, who has granted bioRxiv a license to display the preprint in perpetuity. It is made available under aCC-BY-NC 4.0 International license.

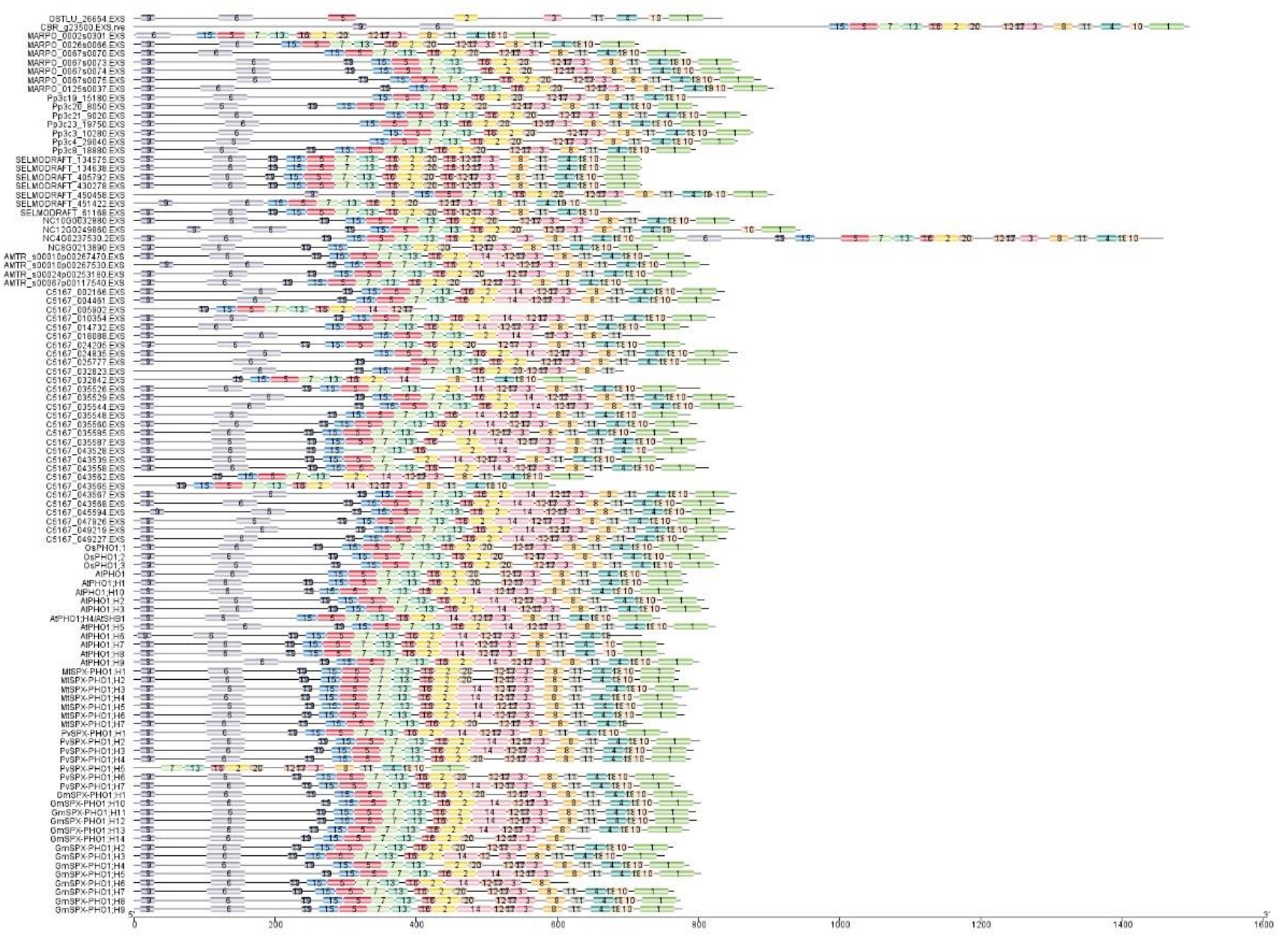

Figure S2. Motif loss and gain in SPX-EXS class genes during the evolution from algae to current Angiosperms 
bioRxiv preprint doi: https://doi.org/10.1101/2021.08.24.457498; this version posted August 24, 2021. The copyright holder for this preprint (which was not certified by peer review) is the author/funder, who has granted bioRxiv a license to display the preprint in perpetuity. It is made available under aCC-BY-NC 4.0 International license.
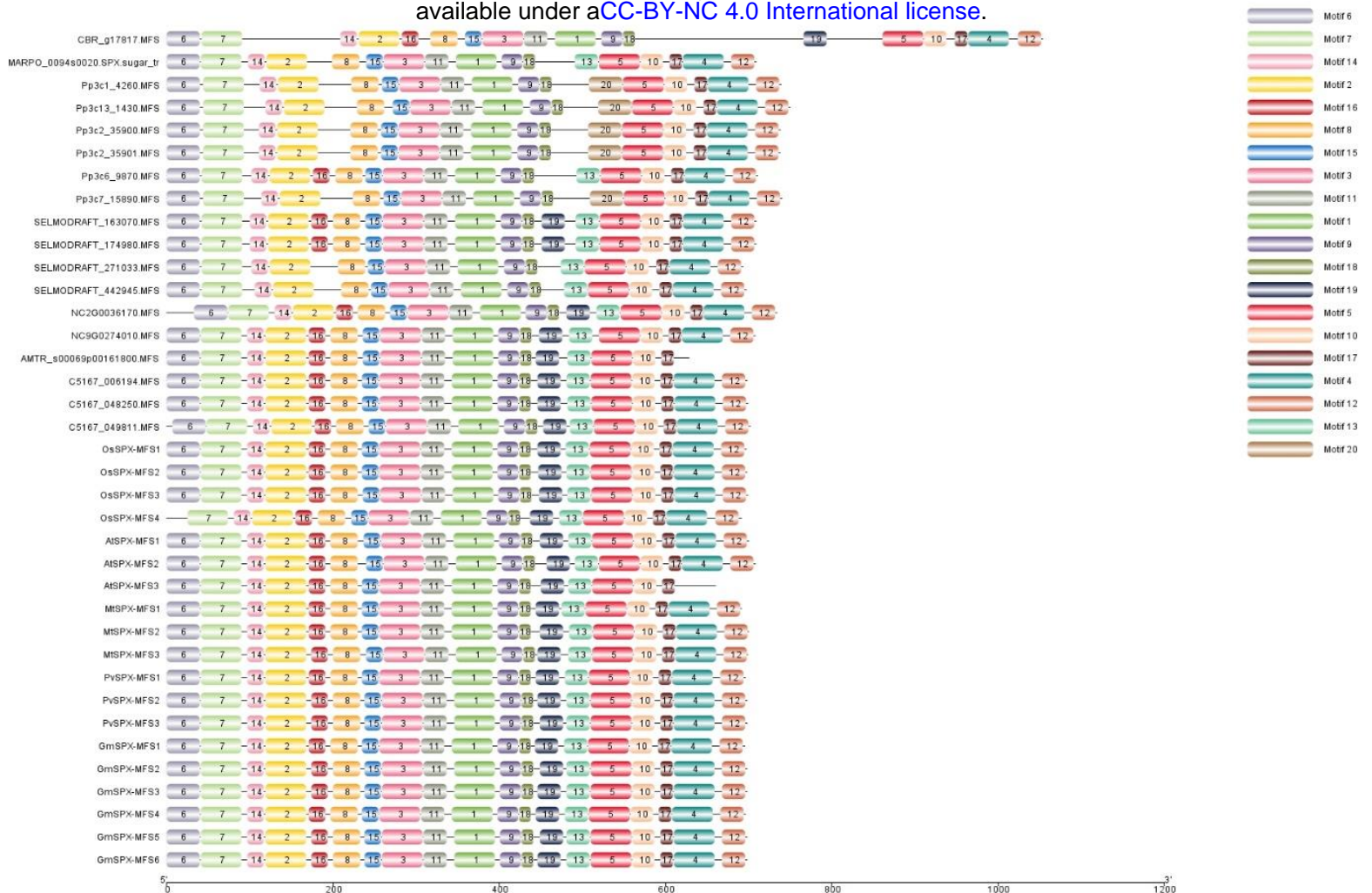

Figure S3. Motif loss and gain in SPX-MFS class genes during the evolution from algae to current Angiosperms 
bioRxiv preprint doi: https://doi.org/10.1101/2021.08.24.457498; this version posted August 24, 2021. The copyright holder for this preprint (which was not certified by peer review) is the author/funder, who has granted bioRxiv a license to display the preprint in perpetuity. It is made available under aCC-BY-NC 4.0 International license.

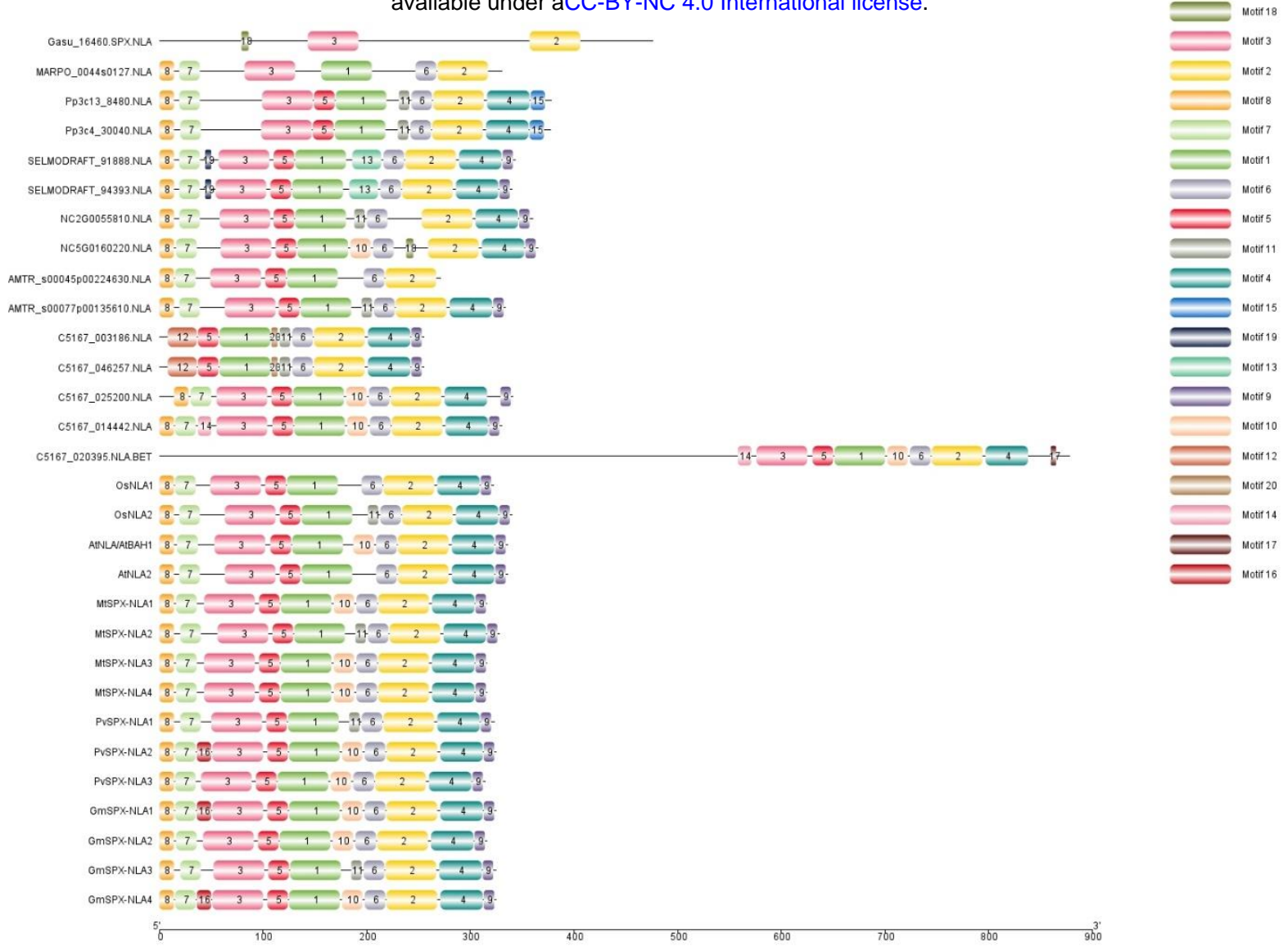

Figure S4. Motif loss and gain in SPX-RING class genes during the evolution from algae to current Angiosperms 
bioRxiv preprint doi: https://doi.org/10.1101/2021.08.24.457498; this version posted August 24, 2021. The copyright holder for this preprint (which was not certified by peer review) is the author/funder, who has granted bioRxiv a license to display the preprint in perpetuity. It is made available under aCC-BY-NC 4.0 International license.

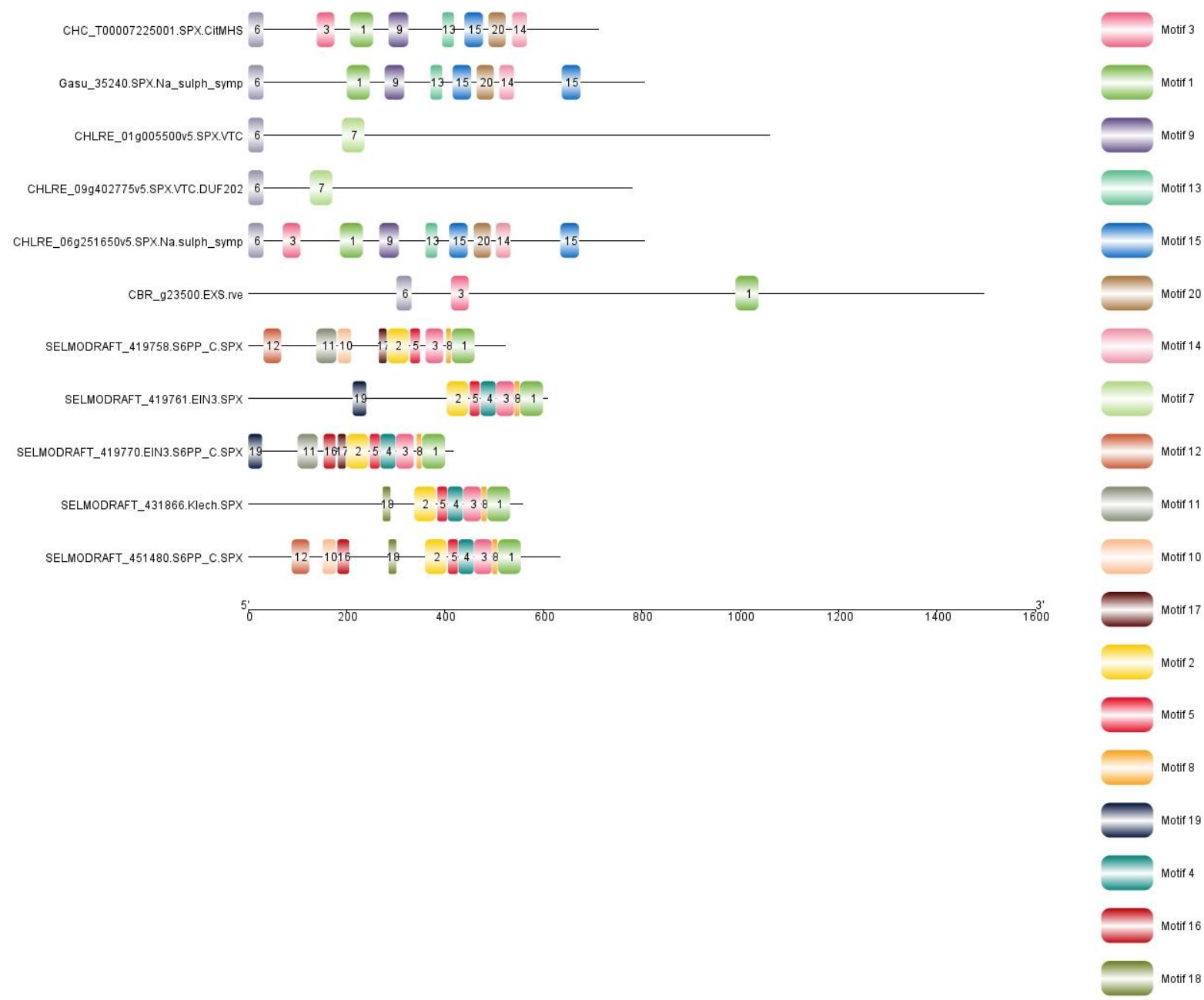

Figure S5. Motifs specifically-found in the new classes of SPX proteins in basal plants 
bioRxiv preprint doi: https://doi.org/10.1101/2021.08.24.457498; this version posted August 24, 2021. The copyright holder for this preprint (which was not certified by peer review) is the author/funder, who has granted bioRxiv a license to display the preprint in perpetuity. It is made available under aCC-BY-NC 4.0 International license.

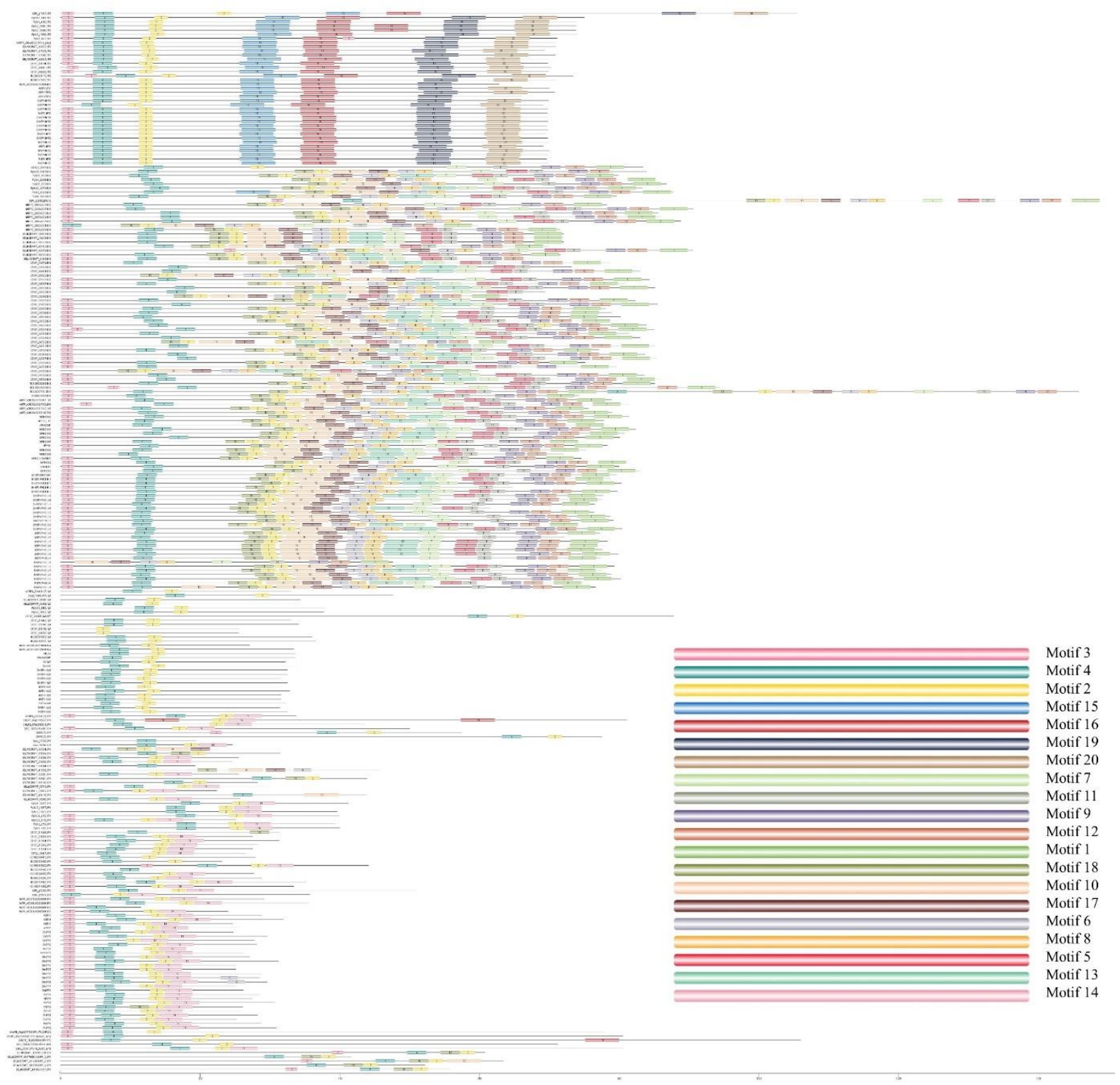

Figure S6. Motif loss and gain of all SPX proteins during the evolution from algae to current Angiosperms 
bioRxiv preprint doi: https://doi.org/10.1101/2021.08.24.457498; this version posted August 24, 2021. The copyright holder for this preprint (which was not certified by peer review) is the author/funder, who has granted bioRxiv a license to display the preprint in perpetuity. It is made available under aCC-BY-NC 4.0 International license.
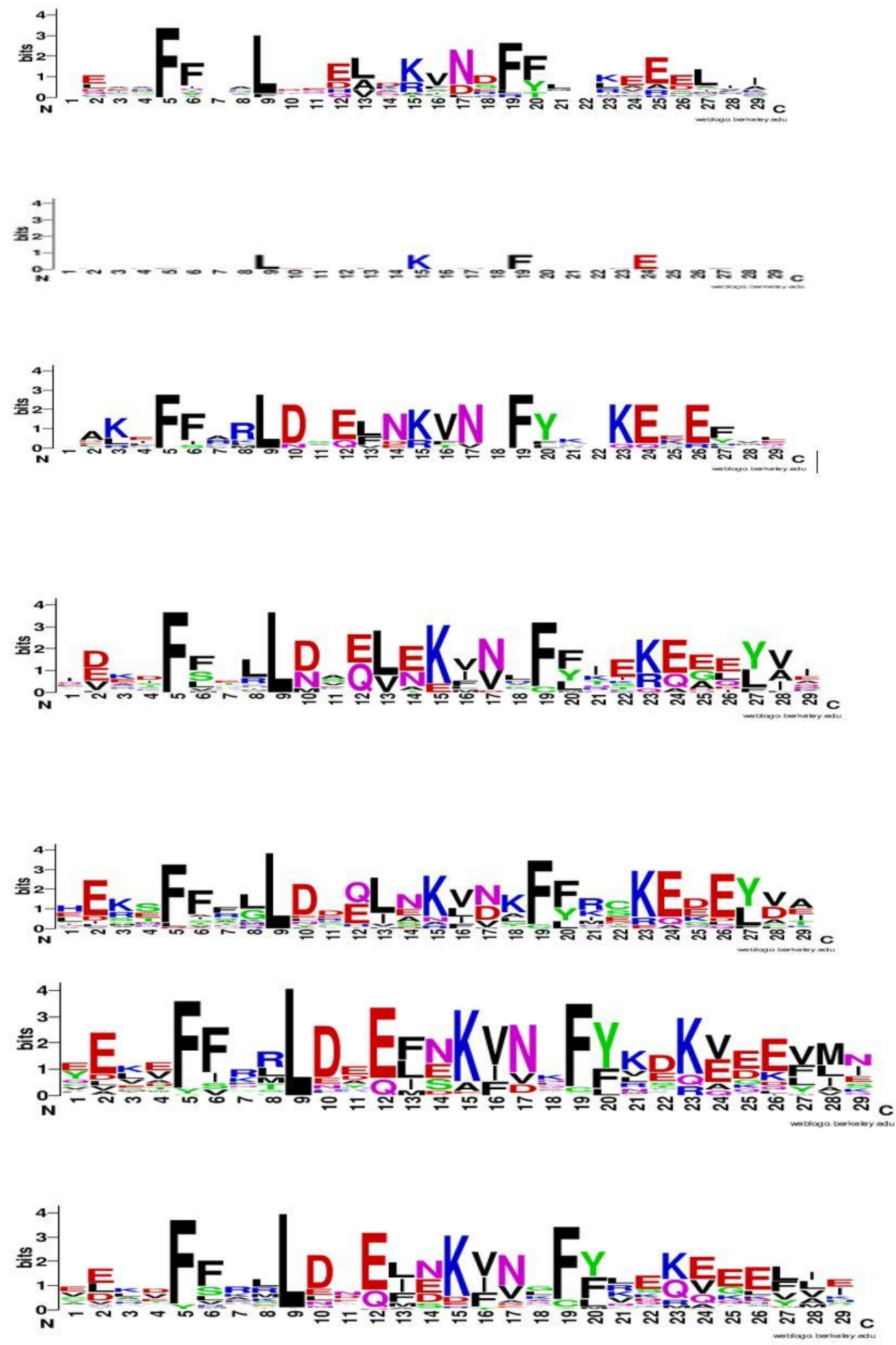

Figure S7. Consensus sequences of motif 4 in SPX domain conserved in whole SPX proteins; in different phyla. Order of phyla from up to down: algae (C.reinhardttii, O. lucimarinus, G. sulfuraria, C. crispus, C. merolae), charophytes (C. braunii), liverwort (M. polymorpha), bryophytes ( $P$. patens), lycophytes ( $S$. moellendorffii), basal angiosperms (A. thricopoda, $P$. sumniferum, N. colorata), and current angiosperm (Arabidopsis, rice, soybean, common bean, alfalfa). 

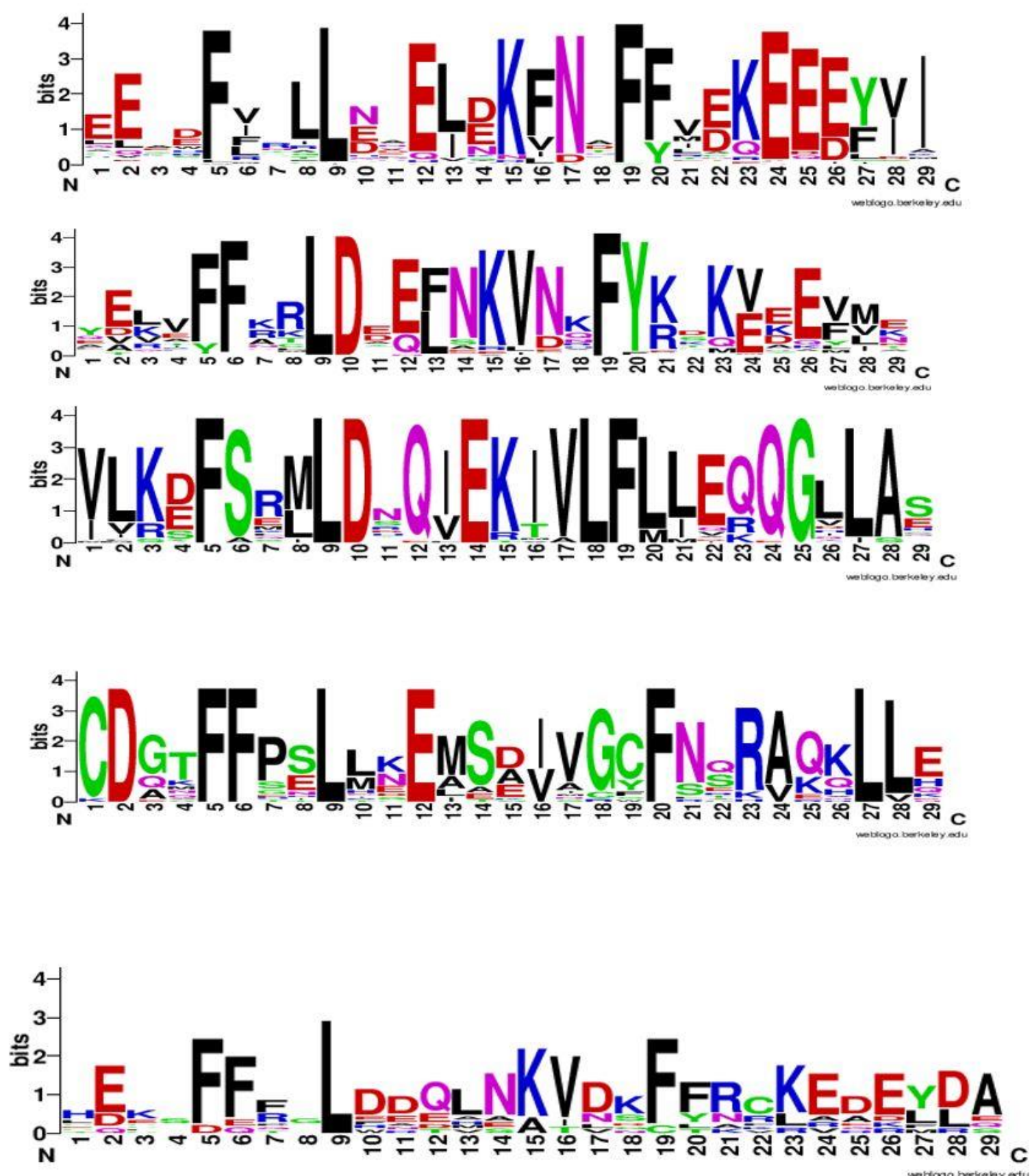

Figure S8. Consensus sequences of motif 4 in SPX domain conserved in whole SPX proteins; in different classes. Order of different classes from up to down: SPX, EXS, MFS, RING, new identified classes. 
bioRxiv preprint doi: https://doi.org/10.1101/2021.08.24.457498; this version posted August 24, 2021. The copyright holder for this preprint (which was not certified by peer review) is the author/funder, who has granted bioRxiv a license to display the preprint in perpetuity. It is made available under aCC-BY-NC 4.0 International license.
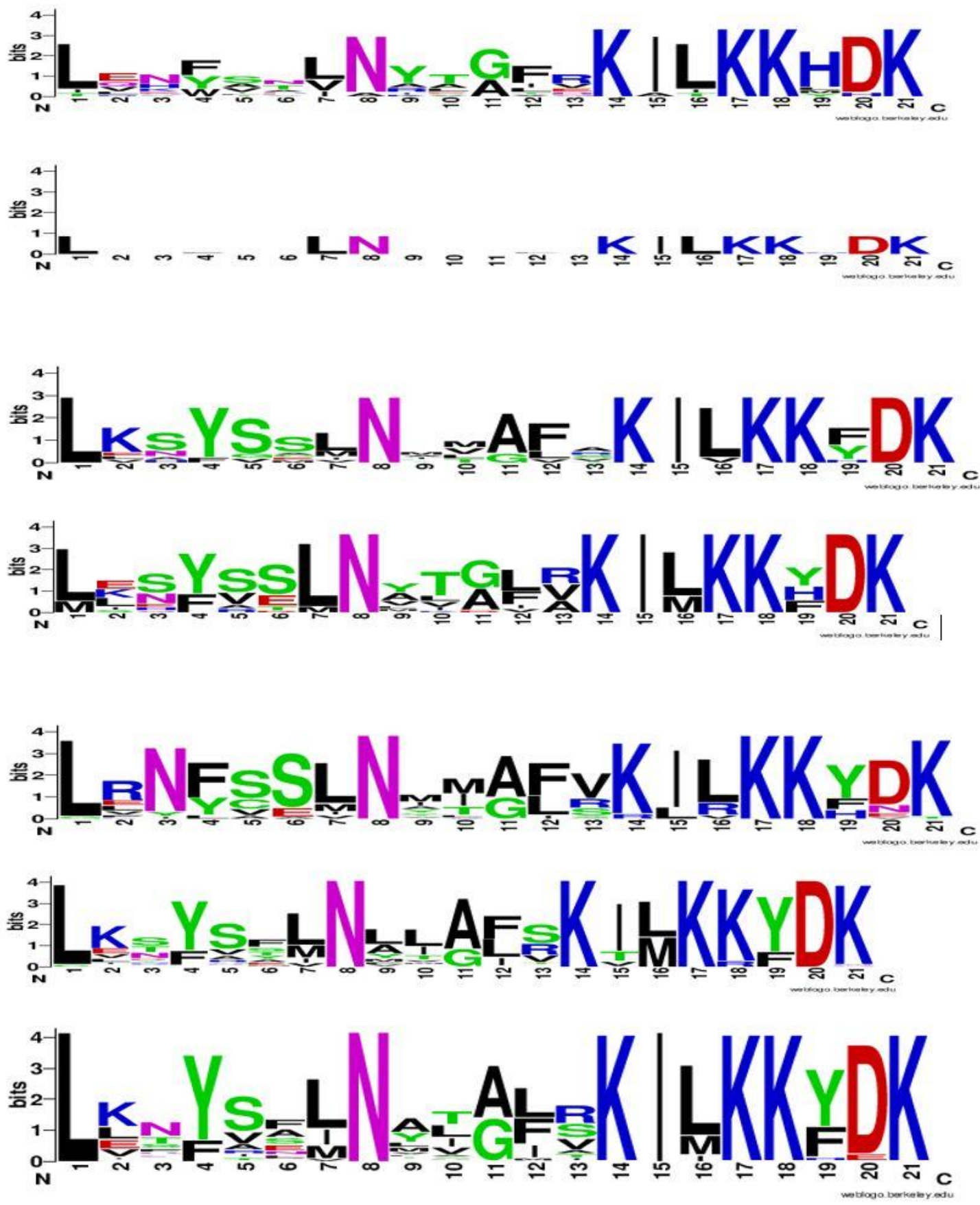

Figure S9. Consensus sequences of motif 2 in SPX domain conserved in whole SPX proteins; in different phyla. Order of phyla from up to down: algae (C.reinhardttii, O. lucimarinus, G. sulfuraria, C. crispus, C. merolae), charophytes (C. braunii), liverwort (M. polymorpha), bryophytes ( $P$. patens), lycophytes (S. moellendorffii), basal angiosperms (A. thricopoda, $P$. sumniferum, N. colorata), and current angiosperm (Arabidopsis, rice, soybean, common bean, alfalfa). 
bioRxiv preprint doi: https://doi.org/10.1101/2021.08.24.457498; this version posted August 24, 2021. The copyright holder for this preprint (which was not certified by peer review) is the author/funder, who has granted bioRxiv a license to display the preprint in perpetuity. It is made available under aCC-BY-NC 4.0 International license.
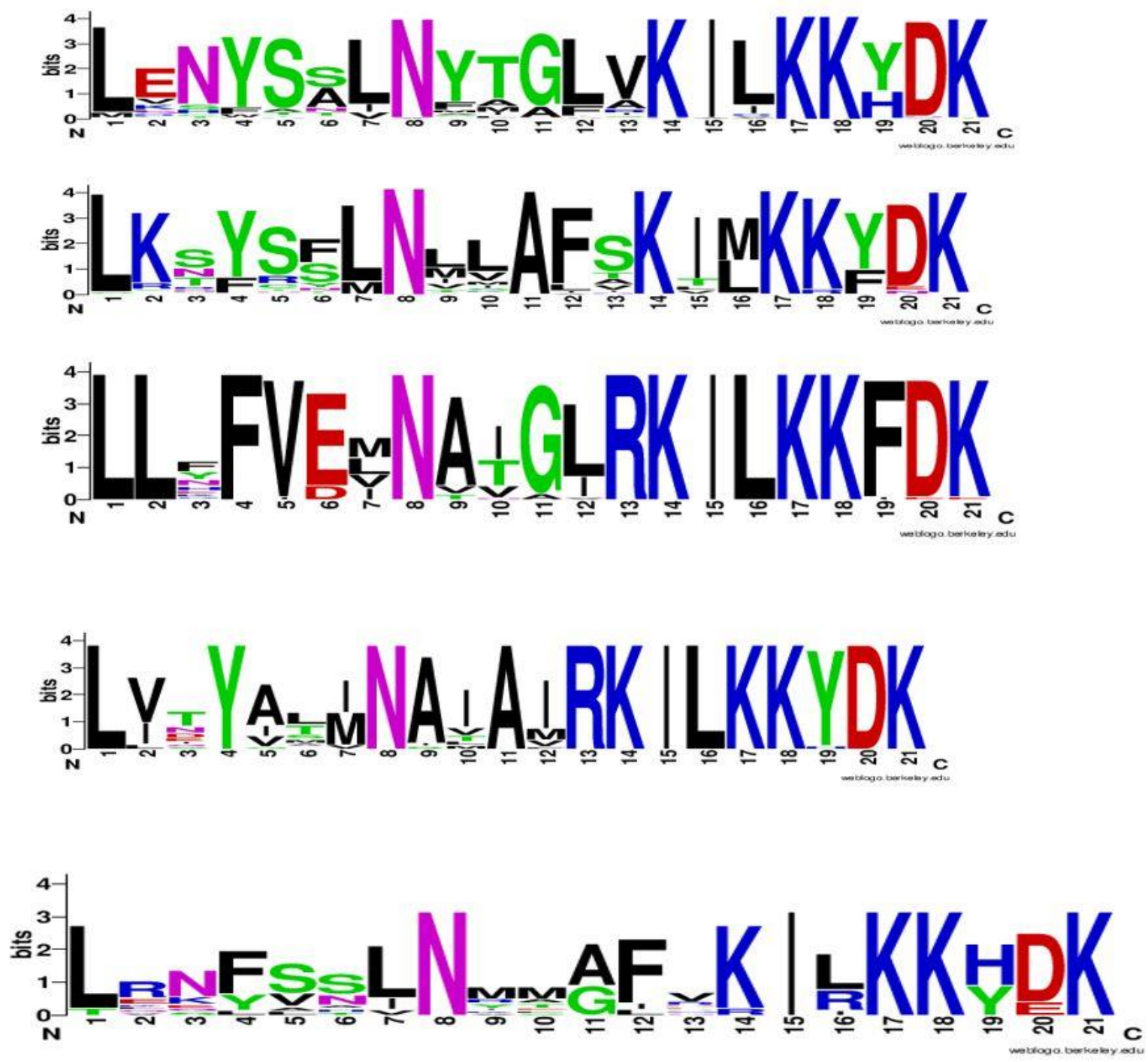

Figure S10. Consensus sequences of motif 2 in SPX domain conserved in whole SPX proteins; in different classes. Order of different classes from up to down: SPX, EXS, MFS, RING, new identified classes. 
bioRxiv preprint doi: https://doi.org/10.1101/2021.08.24.457498; this version posted August 24, 2021. The copyright holder for this preprint (which was not certified by peer review) is the author/funder, who has granted bioRxiv a license to display the preprint in perpetuity. It is made available under aCC-BY-NC 4.0 International license.

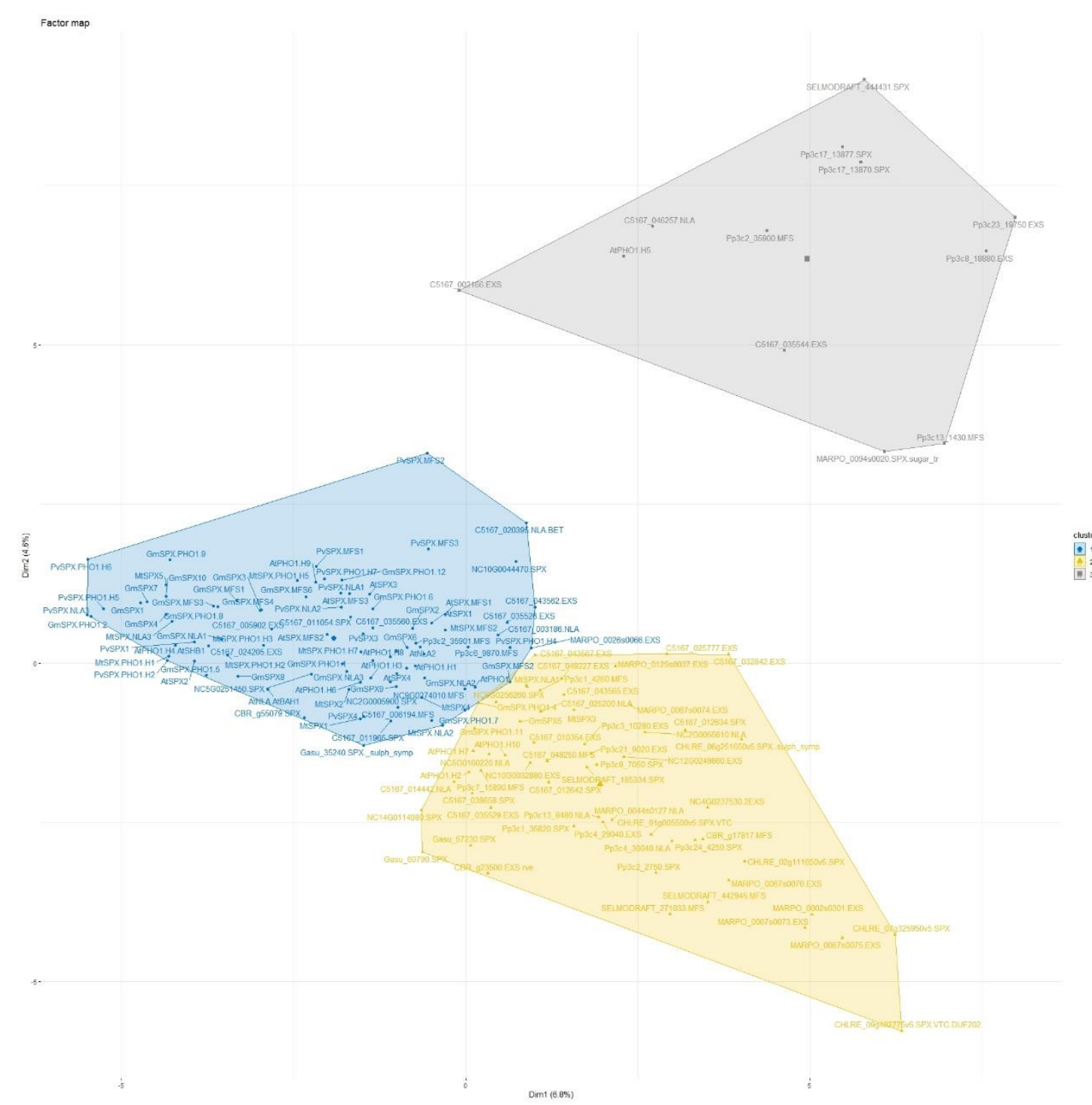

Figure S11. Hierarchical Clustering on Principal Components (HCPC) of SPXs in the lower plants and current Angiosperms based on presence or absence of Cis-acting elements in their promoters. 
bioRxiv preprint doi: https://doi.org/10.1101/2021.08.24.457498; this version posted August 24, 2021. The copyright holder for this preprint (which was not certified by peer review) is the author/funder, who has granted bioRxiv a license to display the preprint in perpetuity. It is made available under aCC-BY-NC 4.0 International license.

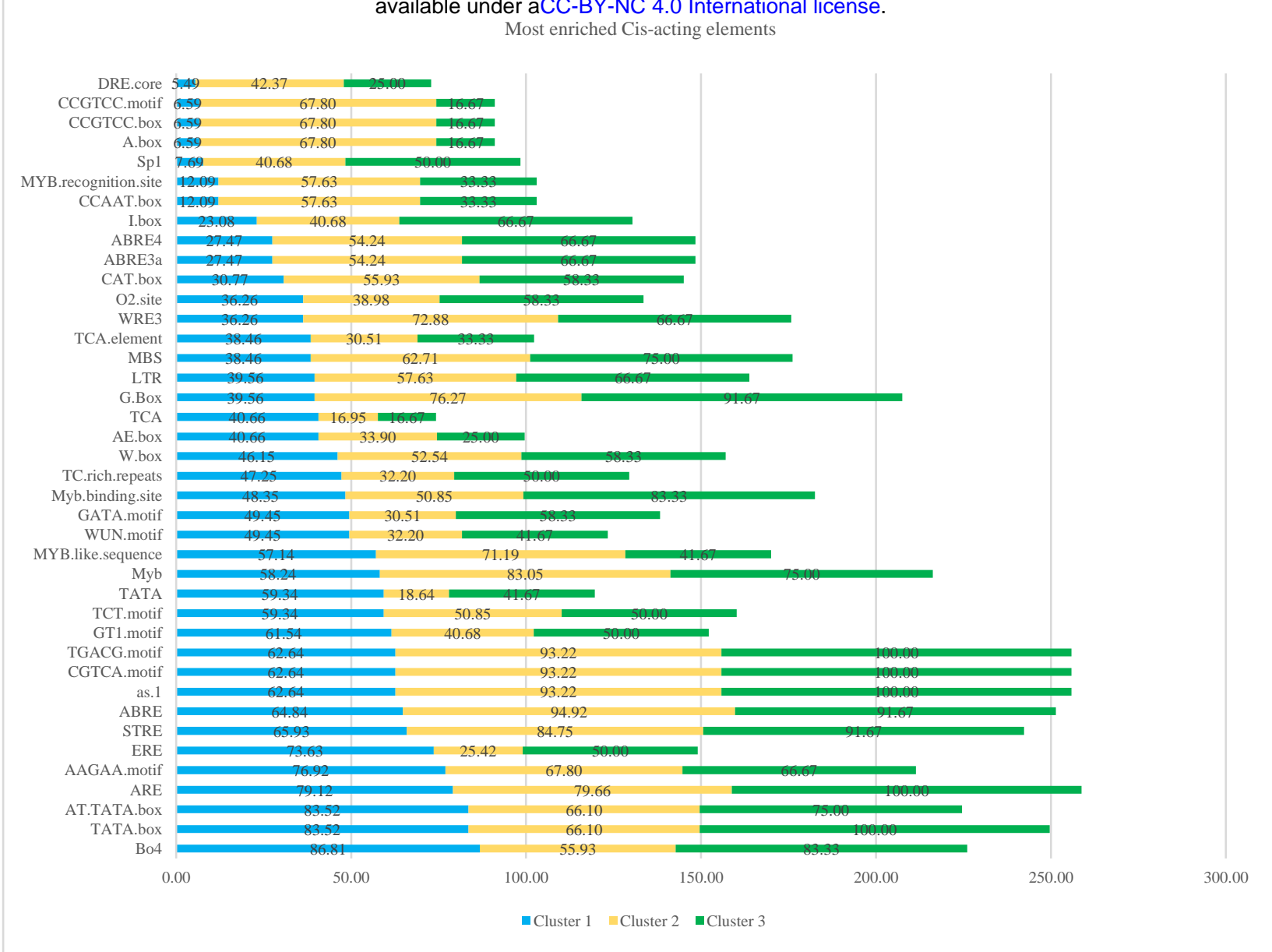

Figure S12. Production of genes in each cluster containing the most frequent Cis-acting elements. The clusters were shown in different colors: cluster $1=$ blue, cluster $2=$ yellow, and cluster $3=$ green . 
bioRxiv preprint doi: https://doi.org/10.1101/2021.08.24.457498; this version posted August 24, 2021. The copyright holder for this preprint (which was not certified by peer review) is the author/funder, who has granted bioRxiv a license to display the preprint in perpetuity. It is made

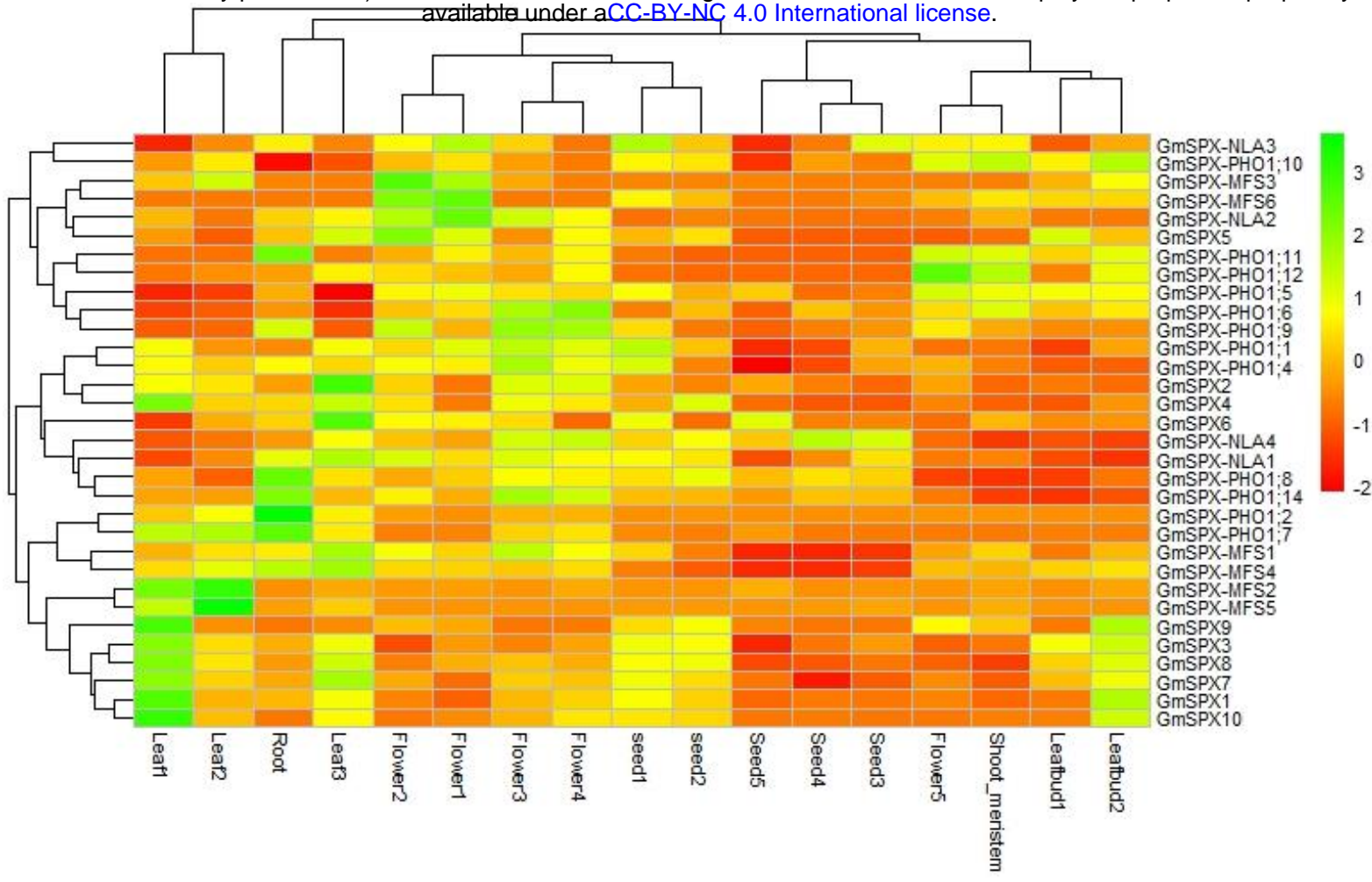

Figure S13. Expression levels of GmSPXs in the different developmental stages of different tissues. Using data from PRJNA238493 bioproject. 
bioRxiv preprint doi: https://doi.org/10.1101/2021.08.24.457498; this version posted August 24, 2021. The copyright holder for this preprint (which was not certified by peer review) is the author/funder, who has granted bioRxiv a license to display the preprint in perpetuity. It is made
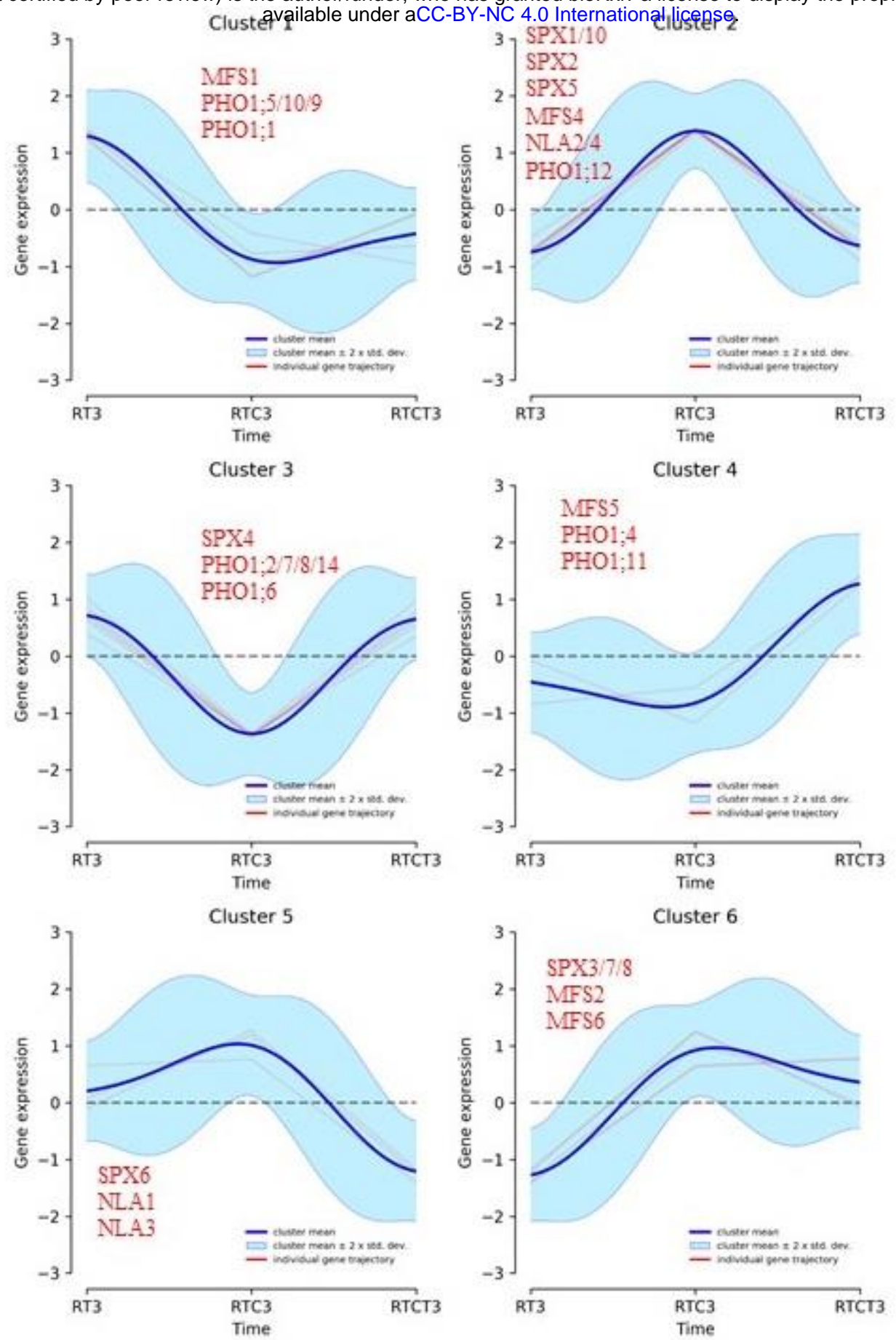

Figure S14. Regulation of SPX genes by phosphate starvation in the roots. DPGP analysis was performed for expression pattern of GmSPXs in roots during three time-points; RT $=$ P deficiency, RTC $=$ P deficiency and recovery, and RTCT $=$ P deficiency, recovery, and second P deficiency. Shown are clustered trajectories of GmSPX genes. The cluster means are in blue, the individual SPX genes are shown in red. Using data from PRJNA544698 bioproject. 
bioRxiv preprint doi: https://doi.org/10.1101/2021.08.24.457498; this version posted August 24, 2021. The copyright holder for this preprint (which was not certified by peer review) is the author/funder, who has granted bioRxiv a license to display the preprint in perpetuity. It is made
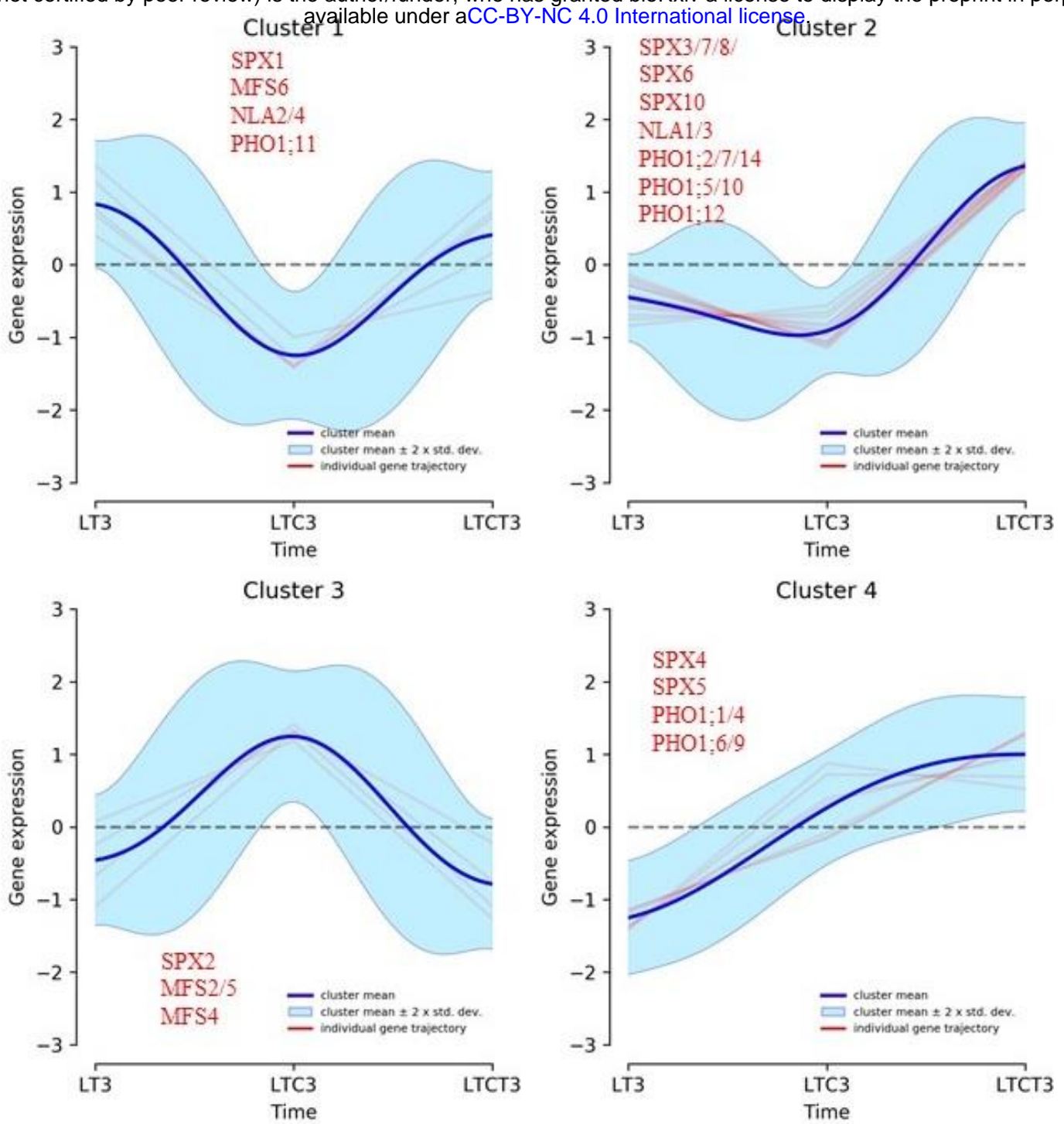

Figure S15. Regulation of SPX genes by phosphate starvation in the leaves. DPGP analysis was performed for expression pattern of GmSPXs in leaves during three time-points; RT= P deficiency, RTC $=$ P deficiency and recovery, and RTCT $=\mathrm{P}$ deficiency, recovery, and second P deficiency. Shown are clustered trajectories of GmSPX genes. The cluster means are in blue, the individual SPX genes are shown in red. Using data from PRJNA544698 bioproject. 
bioRxiv preprint doi: https://doi.org/10.1101/2021.08.24.457498; this version posted August 24, 2021. The copyright holder for this preprint (which was not certified by peer review) is the author/funder, who has granted bioRxiv a license to display the preprint in perpetuity. It is made

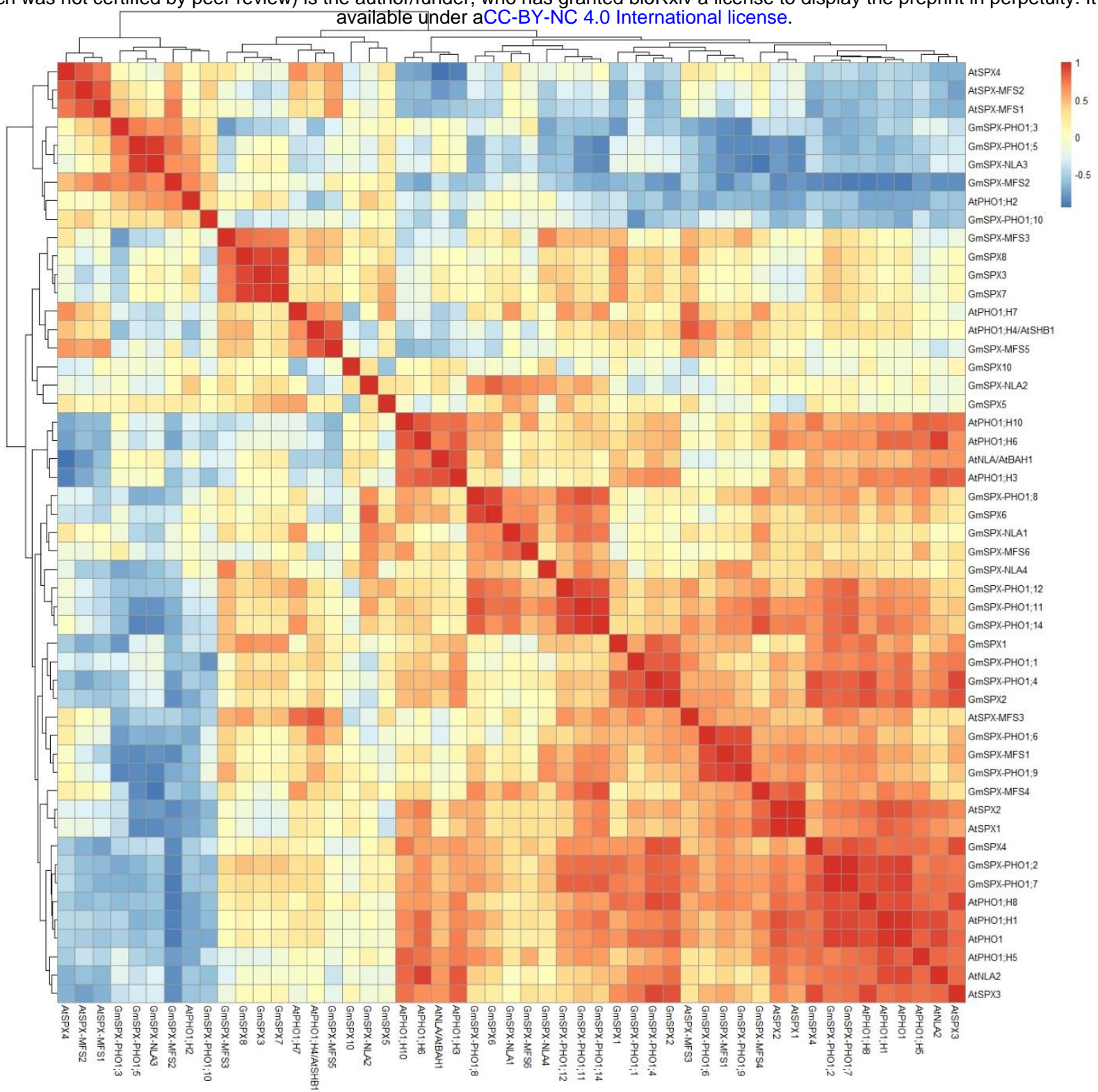

Figure S16. Correlation heat map of SPX genes in soybean and Arabidopsis using RNA-seq datasets from three different zones of roots (GSE64665). 